\title{
ORIGEM DE CLASSE, GÊNERO E TRANSMISSÃO DAS DESIGUALDADES NO BRASIL
}

\section{José Alcides Figueiredo Santos (1)}

E-mail: jose.alcides@uff.edu.br

(1) Professor do Programa de Pós-graduação em Ciências Sociais e do Centro de Pesquisas Sociais, Universidade Federal de Juiz de Fora (UFJF), Juiz de Fora, MG, Brasil.

DOI: $10.1590 / 3610711 / 2021$

\section{Introdução}

São investigadas neste trabalho as relaçóes entre origem de classe, gênero e transmissão intergeracional das desigualdades socioeconômicas no Brasil. O estudo aborda de modo articulado a associação total e direta entre origem de classe e renda dos filhos, as mudanças de padrốes no curso do tempo, a associação direta em diferentes níveis educacionais e a evolução temporal dos retornos da educação por gênero, tanto em geral quanto por origem de classe. Estudos já publicados investigaram a associação entre origem de classe e destino social, focalizando o acesso ao topo social e as recompensas de renda dos filhos (Figueiredo Santos, 2019 e 2020), e mostraram resultados convergentes nas questóes comuns investigadas. A origem de classe privilegiada, sem alteraçóes ponderáveis, continua

Artigo recebido em: 19/09/2020

Aprovado em:18/03/2021 a transmitir as desigualdades socioeconômicas no Brasil entre as gerações. Este artigo dá continuidade a esta linha de investigação, agregando a ela novas dimensões. A análise da associação entre origem de classe e recompensas de renda dos filhos é realizada em separado, por gênero. Em todas as questóes de pesquisa, além disso, são analisados os padróes de associação que se manifestam em diferentes níveis $\mathrm{da}$ distribuição da renda. Assim, pretende caracterizar e analisar, de forma combinada, os padróes de associação por origem de classe considerando suas possíveis variações por gênero e níveis da distribuição da renda.

O estudo modela os padróes diferenciados de gênero que podem se manifestar na transmissão intergeracional das desigualdades. Desigualdades de status de gênero estáo assentadas em crenças culturais compartilhadas que associam maior valor social e competência a pessoas de um grupo, em vez de outro. O impacto e reforço dessas desigualdades de status, por outro lado, dependem das desigualdades posicionais 
de recursos e poder entre homens e mulheres na sociedade (Ridgeway, 2012). As desigualdades de recursos e poder entre gêneros podem estabelecer diferenças de trajetória, da origem ao destino, entre homens e mulheres. $\mathrm{O}$ interesse central desse artigo, no entanto, está na desigualdade de origem de classe. Os resultados são apresentados em separado por gênero, o que traz à superfície as discrepâncias de gênero; mas tais categorias não são diretamente contrastadas. No desenho da investigação, a relação focal é entre origem de classe e renda dos filhos; o gênero representa um contexto que pode alterar esta relação, ou seja, acentuá-la ou atenuá-la, no sentido favorável ou desfavorável a uma categoria, devido à interação entre origem de classe e gênero. Classe social pode ser considerada um fator primário, já que a hierarquia de classe e a herança de classe explicam porque as desigualdades de mobilidade social se formam. Gênero seria um fator secundário, significativo no sentido de ser capaz, em certo grau, de modificar o efeito primário de classe (Bukodi e Goldthorpe, 2020).

Os estudos de mobilidade social focalizam a associação entre a condição socioeconômica dos pais e dos filhos. Quanto maior o grau de associação, menor a mobilidade. Quanto menor a associação, mais a trajetória dos filhos se autonomiza em relação ao condicionamento da origem. As principais questóes e abordagens têm sido articuladas no âmbito do triângulo analítico formado pelas conexôes entre origem social, mediação educacional e destino social. Em grande parte da literatura internacional, não tem sido dedicada tanta atenção, como um elo analítico especialmente esclarecedor, à relaçáo direta entre origem e destino, ou seja, a associação não mediada pela educação e entre pessoas do mesmo nível educacional. Além disso, a noção de mobilidade relativa, ou fluidez social, que desconsidera as implicaçóes das mudanças estruturais para o regime de mobilidade social, tem dominado o campo de estudos desde os anos 1990. Entretanto, questôes de interesse na transmissão intergeracional da desigualdade podem ser recolocadas, ou vistas de um ângulo revelador, quando se focaliza a influência direta da origem social em meio às mudanças estruturais.

Esse trabalho inspira-se nas orientaçóes e estratégias de uma nova investigação comparativa internacional sobre a transmissão de desigualdades (Bernardi e Ballarino, 2016a). O estudo em questão focalizou o que acontece no elo direto entre origem e destino após ser controlada a mediação promovida pelo sistema educacional. De modo complementar, investigou a trajetória de quem adquire o mesmo nível educacional, mas tem desigualdade de origem, como estratégia para testar a chamada hipótese meritocrática baseada em educação. Recorreu à noção de "vantagem compensatória" para realçar como a origem age quando a mediação educacional fracassa. O conceito deriva do insight central de que "as trajetórias do curso de vida de individuos de origens privilegiadas são menos dependentes de resultados negativos anteriores" (Bernardi, 2014, p.75).

Assim como no estudo de referência, no centro da estratégia deste artigo está a questão da associação direta entre origem e destino social não mediada pela educação. Esta estratégia organiza o exame da proposição de que a educação seria o grande equalizador social na sociedade contemporânea. Em termos de lógica teórica interna, e de validação externa, esta proposição supóe que a associação direta entre origem e destino social, após controlar a aquisição educacional, seja igual ou perto de zero ao longo do tempo. A tese geral do papel da educação como o grande equalizador social, por outro lado, tem sido recolocada nos últimos tempos em termos dos efeitos diferenciados nos diferentes níveis educacionais (Bernardi e Ballarino, 2016b).

Estudos têm sugerido que a associação direta entre origem e destino seria tanto menor quanto maior for o nível de educação alcançado. Uma parte desta literatura atribui tal fenômeno ao funcionamento mais meritocrático do mercado de trabalho para os altamente educados (Hout, 1988; Breen e Jonsson, 2007). Análises de natureza descritiva teriam gerado na sociologia um duradouro "consenso" sobre o papel equalizador da educação em promover aumento da mobilidade pelo enfraquecimento do efeito direto da origem na transmissão das desigualdades (Fiel, 2020). A ideia de que a educação superior seria o grande equalizador social ou um poderoso redutor dos efeitos da desigualdade de origem, no entanto, vem sendo crescentemente relativizada e contestada em trabalhos recentes, sobretudo com o uso de novos dados ou novas estratégias (Bernardi e Ballarino, 
2016a; Zhou, 2019; Witteveen e Attewell, 2020; Oh e Kim, 2020; Fiel, 2020; Bernardi e Gil-Hernández, 2020; Figueiredo Santos, 2019 e 2020).

A educação é um fator importante na persistência intergeracional da desigualdade na medida em que tiver um efeito direto relevante em empregos, recompensas e outros benefícios, após controlar por origem social e habilidades cognitivas. O papel da educação na transmissão de vantagens de origem social depende da desigualdade de oportunidade educacional e do valor econômico da educação (Hout, 2012). Na atualidade, dois fatores principais estariam, segundo a literatura econômica e sociológica mais influente, afetando a evolução dos retornos educacionais no curso do tempo. A mudança tecnológica estaria reduzindo o valor de mercado dos menos qualificados. $\mathrm{O}$ aumento da oferta educacional, por outro lado, estaria rebaixando o valor sinalizador das qualificaçóes para os empregadores. Os dois mecanismos poderiam estar em ação ao mesmo tempo (Bernardi e Ballarino, 2014 e 2016b). Alteraçôes que estejam ocorrendo nestes componentes podem potencialmente afetar a transmissão intergeracional da desigualdade, a trajetória de grupos que ancoram na escolaridade suas estratégias de sucesso na mobilidade social ou, então, no sentido oposto, revelar que formas variadas de recursos e barreiras se cristalizam na classe social, e compensam o enfraquecimento da mediação educacional.

As relaçôes entre origem e destino são estudadas com modelos de regressão que captam os impactos, nelas, das mudanças estruturais. Esse estudo focaliza as dimensões ou manifestações da mobilidade social que emergem especialmente da interação entre expansão educacional e mudança da estrutura do emprego. A expansão educacional pode afetar, ao longo do tempo, os retornos educacionais, assim como a mudança ocupacional poder ter consequência para a associação entre origem e destino. $\mathrm{Na}$ confluência de tendências e processos estruturais podem ocorrer mudanças nas relaçōes entre origem e destino por nível educacional.

As questóes introduzidas sinalizam que este estudo não focaliza a mobilidade relativa, ou seja, a associação líquida entre origem e destino, ao serem descontados os efeitos das mudanças estruturais (Goldthorpe,
2016, p. 96). Os estudos sobre mobilidade social no Brasil têm estado em grande medida centrados na mobilidade relativa, o que reflete a tendência dominante da pesquisa internacional desde os anos 1990. Por outro lado, ao focalizar a renda dos filhos no destino, o estudo náo pretende abordar a mobilidade absoluta no sentido usual da pesquisa de estratificação social, ou seja, como "padróes de fluxo das origens aos destinos que podem ser observados na tabela de mobilidade" (Breen, Mood e Jonsson, 2016, p. 41).

Escolhas diferenciadas em relação ao estudo internacional de referência foram incorporadas nos trabalhos já publicados pelo autor, em termos de esquema de classe, modelos estatísticos e efeitos estimados (Figueiredo Santos, 2019 e 2020). Este artigo faz uma aplicação ampla da regressão quantílica em todas as questôes de pesquisa, usando como métrica comum diferenças proporcionais nos resultados. O efeito da origem social no destino é conceituado em termos de oportunidades de vida, e mensurado pela renda atual dos filhos. Inspirado no estudo comparativo internacional (Bernardi e Ballarino, 2016a), o artigo organiza-se em torno de quatro questóes de pesquisa comuns à linha de investigaçáo, visando expandir em dimensōes relevantes os resultados já obtidos: 1) Existe uma associação direta entre origem de classe e recompensas de renda dos filhos, além do efeito mediado pela educaçáo? 2) A associação intergeracional líquida, ou seja, o efeito direto da origem, após controle da educaçáo, declinou no tempo entre as coortes? 3) A associação intergeracional varia por níveis de escolaridade ou, de modo mais específico, o efeito da origem social na renda dos filhos é menor entre indivíduos mais educados? 4) A associaçâo entre a educação dos indivíduos e as recompensas de renda tem variado entre as coortes, ou seja, os retornos econômicos da educação têm aumentado ou diminuído no tempo?

\section{Distribuiçáo de classe e educaçáo entre coortes por gênero}

O desenho da investigaçáo serve para gerar dados que apresentam contextualizaçôes informativas das transformações estruturais que impactam nas relaçôes entre origem, educação e destino nas coortes 
Tabela 1. Distribuiçáo percentual entre origem de classe e nível educacional do filho/a, por coorte e gênero, com totais por origem e educaçáo, mais classe e renda atual do filho/a, Brasil.

\begin{tabular}{|c|c|c|c|c|c|c|c|c|c|c|}
\hline \multirow{2}{*}{$\begin{array}{l}\text { Origem de } \\
\text { Classe }\end{array}$} & \multicolumn{2}{|c|}{ Filho/a 2014* } & \multicolumn{4}{|c|}{ Coorte de 1948-57 } & \multicolumn{4}{|c|}{ Coorte de 1978-87 } \\
\hline & Classe & Renda & Fund. & Médio & Superior & Total & Fund. & Médio & Superior & Total \\
\hline \multicolumn{11}{|c|}{ HOMEM } \\
\hline \multirow{2}{*}{ Topo Social } & \multirow{2}{*}{15,1} & \multirow{2}{*}{6500} & 32,8 & 26,8 & 40,4 & 100,0 & 13,6 & 41,1 & 45,3 & 100,0 \\
\hline & & & 3,2 & 13,2 & 27,1 & 7,3 & 3,4 & 10,6 & 35,1 & 10,9 \\
\hline \multirow{2}{*}{ Qual./Super. } & \multirow{2}{*}{8,0} & \multirow{2}{*}{3200} & 37,7 & 30,5 & 31,8 & 100,0 & 17,0 & 56,1 & 27,0 & 100,0 \\
\hline & & & 2,5 & 10,1 & 14,4 & 4,9 & 2,7 & 9,2 & 13,3 & 6,9 \\
\hline \multirow{2}{*}{ Peq. Ativos } & \multirow{2}{*}{16,8} & \multirow{2}{*}{2000} & 84,8 & 10,5 & 4,7 & 100,0 & 60,7 & 31,4 & 7,9 & 100,0 \\
\hline & & & 42,9 & 26,5 & 16,2 & 37,5 & 29,7 & 16,1 & 12,1 & 21,5 \\
\hline \multirow{2}{*}{ Trabalhador } & \multirow{2}{*}{35,1} & \multirow{2}{*}{1700} & 62,5 & 23,2 & 14,4 & 100,0 & 35,0 & 51,0 & 14,1 & 100,0 \\
\hline & & & 11,9 & 22,0 & 18,7 & 14,1 & 18,7 & 28,5 & 23,5 & 23,5 \\
\hline \multirow{2}{*}{ Destituído } & \multirow{2}{*}{25,0} & \multirow{2}{*}{1200} & 81,2 & 11,7 & 7,1 & 100,0 & 53,9 & 40,0 & 6,0 & 100,0 \\
\hline & & & 39,5 & 28,3 & 23,7 & 36,1 & 45,6 & 35,5 & 16,0 & 37,2 \\
\hline \multirow{2}{*}{ Total } & \multirow{2}{*}{100,0} & \multirow{2}{*}{2000} & 74,3 & 14,9 & 10,9 & 100,0 & 44,0 & 42,0 & 14,0 & 100,0 \\
\hline & & & 100,0 & 100,0 & 100,0 & 100,0 & 100,0 & 100,0 & 100,0 & 100,0 \\
\hline \multicolumn{11}{|c|}{ MULHER } \\
\hline \multirow{2}{*}{ Topo Social } & \multirow{2}{*}{14,8} & \multirow{2}{*}{5000} & 28,7 & 25,9 & 45,4 & 100,0 & 6,8 & 28,6 & 64,6 & 100,0 \\
\hline & & & 3,4 & 12,9 & 26,8 & 8,2 & 2,0 & 6,6 & 28,9 & 10,0 \\
\hline \multirow{2}{*}{ Qual./Super. } & \multirow{2}{*}{11,1} & \multirow{2}{*}{2500} & 35,4 & 33,7 & 30,8 & 100,0 & 9,5 & 43,7 & 46,9 & 100,0 \\
\hline & & & 2,7 & 10,7 & 11,6 & 5,2 & 1,9 & 7,2 & 14,9 & 7,1 \\
\hline & & & 79,6 & 12,5 & 7,9 & 100,0 & 47,8 & 38,4 & 13,8 & 100,0 \\
\hline Peq. Ativos & 9,3 & 1500 & 40,7 & 27,1 & 20,1 & 35,6 & 29,1 & 18,9 & 13,1 & 21,2 \\
\hline Trabalbador & 276 & 1300 & 56,6 & 22,7 & 20,8 & 100,0 & 26,5 & 51,2 & 22,4 & 100,0 \\
\hline Irabalhador & $2 /, 6$ & 1300 & 13,8 & 23,4 & 25,3 & 17,0 & 19,5 & 30,5 & 25,7 & 25,6 \\
\hline & & & 80,9 & 12,5 & 6,6 & 100,0 & 45,7 & 43,6 & 10,7 & 100,0 \\
\hline Destituído & 37,2 & 900 & 39,5 & 25,8 & 16,2 & 34,0 & 47,5 & 36,7 & 17,4 & 36,2 \\
\hline & & & 69,6 & 16,4 & 13,9 & 100,0 & 34,8 & 42,9 & 22,3 & 100,0 \\
\hline Total & 100,0 & 1448 & 100,0 & 100,0 & 100,0 & 100,0 & 100,0 & 100,0 & 100,0 & 100,0 \\
\hline
\end{tabular}

Fonte: Elaboração do autor com base na PNAD 2014. * Renda do filho/a em P70.

investigadas. A Tabela 1 combina diferentes distribuiçóes de origem de classe e educaçáo dos descendentes, por gênero, na primeira e última coorte. A regra padrão de leitura dos dados nas células da Tabela é considerar a direção dos valores parciais que totalizam $100 \%$. Os dados revelam como se alterou, no amplo período estudado, a distribuição de classe dos pais e da educação dos filhos/as. Registra a renda atual dos filhos, que será a medida do efeito da origem no destino. Foi escolhido como valor representativo da renda o percentil 70 por estar mais próximo da média, devido à elevada assimetria da distribuição da renda no Brasil. Foi informada a distribuição de classe do filho, visto que a maior parte da renda de todas as fontes está associada ao emprego principal para o ocupado. A informaçáo permite ver também como evoluiu a estrutura do emprego da origem até o destino.

As principais mudanças na distribuiçáo da classe de origem foram a retração da categoria de pequenos ativos e a expansáo do trabalhador típico e do topo social. O processo geral reflete o encolhimento dos estratos agrícolas e a expansão dos demais grupos, associado ao desenvolvimento capitalista e à urbanização. $\mathrm{O}$ topo social ficou maior. $\mathrm{O}$ empregado qualificado cresceu. $\mathrm{O}$ maior crescimento, em termos absolutos e relativos, se deu com o trabalhador típico. O agrupamento destituído, que já era muito grande, teve leve aumento. O quadro de mudança da estrutura social, com foco na variável independente origem de classe, é bastante significativo. Estas tendências para homens e mulheres se intensificam quando 
olhamos para a distribuição de classe dos filhos em 2014. A distribuição final de empregos desfavorece sobretudo as filhas na hipertrofia das posiçóes de classe destituídas. A variável dependente do estudo, no entanto, é a renda dos descendentes. A estatística descritiva sinaliza, desde já, a existência de um prêmio de renda puramente vinculado à origem de classe. O prêmio de origem de classe vantajosa é maior para o homem, e o ônus de origem desvantajosa para a mulher. Este padrão vai ser confirmado mais à frente, com as estimativas ajustadas por regressão quantílica.

Entre a primeira e a última coorte ocorreram alteraçôes muito expressivas na distribuição da educação dos filhos/as. O processo de expansão educacional de décadas reduziu o grupo que possui educação média incompleta ou inferior, denominado Fundamental. $\mathrm{O}$ crescimento mais forte em termos absolutos e relativos se deu na categoria de educação média completa ou superior incompleta. Neste contexto de expansão educacional, foram alteradas as relaçōes entre origem de classe e realizaçáo educacional. Todos os grupos tiveram naturalmente avanços significativos em decorrência da expansão educacional. $\mathrm{Na}$ origem no topo ocorreu a maior expansão da educação superior completa, partindo de uma base que já era alta, em um processo impulsionado pelo desempenho da mulher. $\mathrm{Na}$ origem de trabalhador típico, o ensino superior completo se retraiu, no caso do homem, e estagnou, no caso da mulher, mas houve melhora elevada no nível médio e superior incompleto. $\mathrm{Na}$ origem destituída foi registrada a expansão mais expressiva no nível médio, mas devido à base muito baixa da primeira coorte. Embora o acesso ao ensino superior continue muito minoritário nesta origem, a mulher teve uma trajetória bem melhor do que o homem.

\section{Campo de estudos de mobilidade social no Brasil}

Visando situar o campo de estudos, realizo aqui uma síntese dos estudos sobre as tendências de mobilidade social no Brasil, abarcando trabalhos mais recentes e o tratamento de gênero. Quatro revisōes recentes da literatura podem ser consultadas (Picanço, 2006; Scalon e Figueiredo Santos, 2010; Figueiredo Santos e Scalon, 2018; Ribeiro e Carvalhaes, 2020).
A mobilidade social no Brasil apresenta como característica mais marcante um divisor pronunciado, ou pouca fluidez social, entre o topo social - composto por proprietários, profissionais e administradores - e todas as demais classes abaixo (Ribeiro, 2014). Entretanto, quando se olha para o quadro de conjunto de origens e destinos em particular, mesmo com este fechamento social no topo privilegiado, constata-se uma diminuição da desigualdade de oportunidades de mobilidade social no Brasil no curso do tempo. Esta fluidez social crescente não foi um processo linear, pois estagnou ao final de 1980 e em 1990. A diminuição dos retornos educacionais se apresentou como o principal fator contribuinte para a diminuição das desigualdades de oportunidades no país.

Esta tendência geral de diminuição da desigualdade de oportunidades conviveu com um aumento das vantagens diretas de classe nas décadas de 1990 e 2000 (Torche e Ribeiro, 2010; Ribeiro, 2012). A mobilidade intergeracional estaria aumentando no Brasil em todos os indicadores considerados, ou seja, em termos de classe social, status ocupacional, proxy de "renda permanente" e educação (Ribeiro, 2017a). O contraste entre profissionais e trabalhadores manuais dá uma ideia concreta da magnitude do processo. A vantagem do filho de um profissional (Classe I) de permanecer nesta classe em comparação à de um filho de trabalhador manual qualificado (Classe VI) de ingressar nela, em termos de chances relativas, era de 32 vezes em 1982, 28,5 vezes em 1988 e 21 vezes em 1996; em 2014, caiu para 15 vezes (Ribeiro, 2017b).

Revisão recente da literatura aponta a relativa ausência de trabalhos sobre a "inter-relação entre estratificaçáo e gênero" (Ribeiro e Carvalhaes, 2020, p. 35). Estudo de mobilidade relativa com dados de 1988 constatou uma inexistência de diferenças relevantes de fluidez social entre a mobilidade de homens e de mulheres (Scalon, 1999). Embora a mobilidade absoluta das mulheres tenha sido grande, suplantando a dos homens, conforme dados de 1996, este processo parece refletir basicamente as diferenças na distribuiçẫo das ocupaçôes dos pais e das filhas (Scalon, 2009, p. 28). No período de 1988 a 1996, a diminuição da desigualdade de oportunidades das mulheres decorreu de alteraçóes na composição educacional, ou seja, o seu crescente progresso 
educacional. Entretanto, no final do século, tendo em vista as persistentes desigualdades de gênero no mercado de trabalho, as mulheres ainda dependiam do mercado matrimonial para se aproximar dos padrôes de mobilidade social dos homens (Ribeiro, 2007). Dados de 2008 indicam que, para as mulheres, as tendências de diminuiçáo das desigualdades de oportunidades se devem mais à diminuição das associaçōes entre origem de classe e educação (OE) e educação e destino de classe (ED).

As tendências de diminuiçáo dos retornos educacionais, observadas no período de 1973 a 1996 para os homens, também se mostram válidas para as mulheres em 2008 (Ribeiro, 2012). Não existem estudos publicados de mobilidade social, desagregados por gênero, que usem dados de 2014. Por outro lado, a investigação dos padróes de mobilidade de renda, ao comparar os dados de 1996 e 2014, e as diferenças entre homens e mulheres em 2014, demonstra que, principalmente em termos de posição na distribuição da renda, a democratizaçáo dos diversos níveis de ensino náo foi suficiente para promover uma fluidez socioeconômica intergeracional maior no Brasil. Os resultados revelam poucas diferenças entre o que se observa para as filhas e os filhos (Cruz, 2019).

\section{Métodos: variáveis, dados, modelos e estimativas}

Uma abordagem neomarxista fundamenta a construção da tipologia de classes usada na investigação. Nesta ótica, as divisōes de classe são constituídas por desigualdades de direitos e poderes sobre recursos geradores de valor que instituem vantagens e desvantagens entre categorias (Wright, 1997). O esquema de classes foi ajustado às especificidades da estrutura social do Brasil e tem sido usado em vários estudos de desigualdades de renda, saúde e mobilidade social (Figueiredo Santos, 2005, 2010 e 2014). Neste artigo, aplica-se uma solução agregada que diferencia cinco grandes agrupamentos de classe. $\mathrm{O}$ topo social é formado pelas principais dimensōes geradoras de privilégios de classe, isto é, a propriedade de capital, a posse de conhecimento perito e o exercício de comando ou dominaçáo a serviço de uma organizaçáo. Integram este agrupamento privilegiado todos os empregadores, gerentes e especialistas. Foi usado um critério ampliado do topo social, que inclui os pequenos empregadores, já que, no destino, a renda deste se aproxima do topo privilegiado e que, na origem, inexiste informação sobre número de empregados. Esta ampliação da dimensão de propriedade revelou em estudo precedente, além disso, uma desvantagem de origem ainda maior, para quem vem da base social, em ter acesso, no destino, ao topo social (Figueiredo Santos, 2019).

Outro agrupamento diferenciado de classe é formado pelos não empregadores, que controlam recursos de menor valor ou com potencial de gerar menor valor econômico. Este agrupamento é composto pelas categorias autônomo com ativos e autônomo agrícola. Não foi possível diferenciar o autônomo agrícola precário na origem, segmento de peso demográfico ponderável e que deveria ser alocado no agrupamento destituído. Os empregados qualificados e os supervisores são considerados como um segmento distinto no interior do trabalho assalariado, devido aos vínculos parciais com a posse de qualificaçóes escassas e ao exercício de autoridade em nome da organização empregadora. A categoria majoritária de trabalhador típico caracteriza-se por estar submetida plenamente aos processos conjugados de controle da atividade do agente, e de apropriação dos resultados do trabalho. Por fim, são agregadas as posiçóes destituídas de ativos por mecanismos que levam à exclusão, à insuficiência ou à depreciação de recursos geradores de valor. Compóe este agrupamento o trabalhador elementar, o autônomo precário, o empregado doméstico, o trabalhador de subsistência e o trabalhador excedente (desempregado). O critério de dominância foi usado na mensuraçáo da classe de origem, ou seja, foi considerando o emprego mais elevado entre os pais.

A investigaçáo utiliza os dados do suplemento de mobilidade social da Pesquisa Nacional por Amostra de Domicílios (PNAD) de 2014, respondido por morador de 16 anos de idade ou mais, selecionado aleatoriamente. A amostra analítica é formada por 30991 casos de pessoas de 27 a 66 anos e informaçôes válidas para as variáveis dos modelos. Entretanto, a significância estatística e a precisão das estimativas estáo especialmente associadas, em cada subgrupo e situação específica, ao número de casos e à força do 
efeito, já que um efeito mais forte tende a demandar menos casos. A regressão quantílica, por outro lado, estima efeitos em níveis limiares da distribuição, o que garante mais robustez e gera menos problemas associados à insuficiência de casos. Não foram registradas situaçôes críticas de insuficiência de casos, que poderiam distorcer as respostas às quatro questôes de pesquisa. A desagregação por gênero pode colocar dúvidas em certas estimativas de subgrupo; a tendência pode ser esclarecida pela estimativa agregada, além da comparação entre estimativas sem diferenças ponderáveis em número de casos. Foram referidos na análise certos problemas em estimativas pertinentes aos Gráficos 5 e 6, relativos às mudanças temporais, devido à necessidade de recorrer a interaçôes entre quadros variáveis, o que tende a demandar mais casos. ${ }^{1}$

A variável dependente do estudo é a renda positiva de todas as fontes dos filhos. A desigualdade de ganhos por classe social de origem revela-se maior quando são usadas medidas mais abrangentes de renda (Hansen, 2001). O uso da renda de todas as fontes (income) oferece um ganho em precisão, ao mensurar de modo mais circunstanciado a situação socioeconômica no destino (Witteveen e Attewell, 2020, p. 11). A renda tem a propriedade de abarcar um sentido amplo de transmissão ou redução das vantagens de origem no destino social. Esta característica da variável dependente pode ser explorada de modo mais pleno quando focalizamos diferentes localizações além do centro da distribuição da renda.

O critério ampliado de renda usado neste estudo faz com que uma parcela dos filhos (15\%) não seja economicamente ativa, embora para os aposentados ( $49,4 \%$ do subgrupo fora da PEA) a renda reflita a trajetória de emprego da pessoa. Esta ampliação do alcance dos casos no destino favorece o uso de interaçóes complexas entre variáveis. Seria possível usar a renda familiar total sob a justificativa de ser "a medida mais abrangente de bem-estar econômico" (Torche, 2016, p. 240). A renda familiar absorve as desigualdades existentes dentro das categorias ocupacionais, e os processos que afetam o bem-estar de todos os membros da família, contornando as diferenças de gênero em participação e segregação no trabalho (Fiel, 2020, p. 357). A renda familiar per capita revelou, em estudo no Brasil, uma maior persistência intergeracional do que outros conceitos de renda (Pero e Szerman, 2008). Entretanto, por questão de ajuste, visando focalizar a trajetória do indivíduo selecionado, optou-se por conter a influência no resultado da renda dos demais membros da família.

$\mathrm{Na}$ análise da desigualdade por fatores atribuídos, tal como a origem de classe, que são dados ao indivíduo, ocorre que a maioria dos controles potenciais estará associada a este condicionamento originário. Os controles são justificáveis, em uma abordagem chamada de pré-mercado, na medida em que foram determinados antes do indivíduo entrar no mercado de trabalho (Hällsten, 2013, p. 667-8). Todos os modelos controlam por gênero, cor, coorte e Unidade da Federaçáo (UF) de residência do filho aos 15 anos. Esta última variável controla as diferenças regionais pré-existentes no mercado de trabalho. Estes são os controles básicos equivalentes aos usados no estudo de referência, assim como em outros similares (Bernardi e Ballarino, 2016a). Os resultados estimados, ajustados por estes controles, com a agregação da educação do filho, captam todos os fatores que estão associados à origem de classe. A escolha de controles aproximaria o desenho da pesquisa e o objetivo interpretativo da realizaçáo de generalizaçóes empíricas. Inquirir o que não se sabe - ou não está claramente estabelecido - sobre a realidade existente a partir do que se sabe representa um ato inferencial da tarefa de descrição, pois visa generalizar padrōes amplos de associação (Gerring, 2012, p. 108).

A educação é uma variável chave no estudo, pois se pretende estimar a associação direta de origem e destino após controlar a educaçáo individual. São diferenciadas as principais transiçóes educacionais que influenciam os destinos de classe: sem instrução, fundamental incompleto, fundamental completo, médio incompleto, médio completo, superior incompleto e superior completo. $\mathrm{Na}$ análise da associaçấo intergeracional por níveis educacionais, estes serão agrupados em três grandes categorias (médio incompleto, fundamental ou menos; médio completo ou superior incompleto; superior completo), com a finalidade estimar efeitos interativos mais precisos. As quatro coortes usam intervalos de dez anos, diferenciando pessoas nascidas nos anos de 
1948-1957, 1958-1967, 1968-1977 e 1978-1987. Em todos os modelos estimados foram usadas interações com influência relevante na investigação de cada questão de pesquisa. As interaçóes de duas a quatro variáveis envolveram as variáveis de origem de classe, gênero, coorte e níveis educacionais. Os efeitos interativos, distintos dos efeitos específicos de cada variável, representam o resultado de um efeito sobre um efeito e, por isto, revelam como um efeito muda (Kam e Franzese, 2007).

O estudo utiliza regressão quantílica com a finalidade de estimar os efeitos da origem em diferentes níveis da distribuição da renda. Esta propriedade da regressão quantílica presta-se a examinar a heterogeneidade dos efeitos, através da distribuição de renda, a depender da origem de classe. Os efeitos vão ser estimados aos níveis de quadro percentis (ou quantis) selecionados no conjunto geral dos dados ordenados. Foram selecionados o $25^{\circ}$ percentil (25\% mais pobres), o $50^{\circ}$ percentil (mediana), $75^{\circ}$ percentil ( $25 \%$ mais ricos) e o $90^{\circ}$ percentil $(10 \%$ mais ricos). Nos resultados apresentados, os percentis selecionados vão ser referidos como P25, P50, P75 e P90. A seleção considera a necessidade de preservar número suficiente de casos para detectar associaçóes, e usar um conjunto mais manejável de resultados, já que são feitas estimativas para cinco agrupamentos de origem, separadas por gênero; são usadas interações de duas a quatro variáveis; e são estimados efeitos com foco prioritário no subgrupo seletivo com educação superior completa. As estimativas da regressão quantílica, além de terem um escopo mais amplo, são mais robustas à presença de outliers ou dados dissonantes do conjunto (Cameron e Trivedi, 2009, p. 205).

Deve ser ponderado, para efeito de interpretação, que os coeficientes dos quantis ou percentis na regressão quantílica fornecem informaçóes "sobre efeitos em distribuiçôes e não em indivíduos”. A distinção entre tornar um determinado grupo de pobres (ou ricos) mais ricos (ou mais pobres) e mudar o significado de ser pobre (ou rico) é sutil. Na medida em que a mudança preserva o lugar do indivíduo no ordenamento, um aumento no percentil implica que a pessoa está mais rica, embora seu status relativo se mantenha inalterado. Por outro lado, se ocorrer mudança no ordenamento, pode-se dizer somente que, sejam quem forem os ricos (ou os pobres), eles estão melhor (ou pior) (Angrist e Pischke, 2009, p. 281). A distinção entre efeitos em distribuiçôes e em individuos seria de importância fundamental ao se avaliar os resultados de intervençóes ou tratamentos ao nível dos indivíduos beneficiados ou não por estas medidas. Entretanto, como a presente investigação está focada nas discrepâncias entre grupos de origem, tal problema seria de interesse mais secundário.

Nas estimativas com regressão quantílica foi usado o comando sqreg do Stata, que estima de forma simultânea os coeficientes para cada quantil ou percentil. Os erros padróes foram obtidos por bootstrapping, usando 500 replicaçôes. As diferenças entre as categorias nos gráficos foram representadas por discrepâncias proporcionais nos resultados. Semielasticidade é um híbrido de elasticidade e efeitos marginais (ou parciais) médios, que mede a mudança proporcional, em $\mathrm{Y}$, associada a uma mudança de uma unidade em X. A escala em que a variável dependente é medida não influencia o resultado (Cameron e Trivedi, 2009, p. 335). As medidas baseadas em métrica logarítmica ou elasticidade, diferentemente das medidas de diferenças absolutas, não são influenciadas pelas diferenças de rendas médias associadas aos perfis heterogêneos de idade-ganhos das coortes. A elasticidade é uma medida insensível ao crescimento ou à contração econômica ocorrida, pois mede a associação em termos proporcionais. Neste sentido específico, que remove basicamente as mudanças nas rendas médias, captura um tipo de mobilidade náo absoluta.

Entretanto, a medida é afetada pela extensão da desigualdade em cada coorte, e pelas mudanças na desigualdade entre as coortes. Ceteris paribus, a medida aumenta com o aumento da desigualdade e vice-versa (Torche, 2015b, p. 348-9; Torche, 2015a, p. 44). Elasticidade não equivale à noção de mobilidade relativa, ou de fluidez social, expressa no cálculo de chances relativas (odds ratios), usado na pesquisa de estratificação social. As medidas de elasticidade são, "por definição, afetadas pela distribuição subjacente dos rendimentos ou rendas em que são estimadas” (Fox, Torche e Waldfogel, 2016, p. 532). Uma medida que removesse as mudanças na dispersão da renda estaria 
"mais em linha com o uso de chances relativas dos sociólogos" (Breen, Mood e Jonsson, 2016, p. 43).

A semi-elasticidade usada neste estudo, como uma medida híbrida de elasticidade e efeitos parciais, reflete o impacto de forças estruturais na relação entre origem de classe e destino de renda. As estimativas foram realizadas pelo comando margins do Stata, usando opção eydx, e depois transformadas em gráficos pelo marginsplot. A opçáo eydx estima a semi-elasticidade, ou seja, a mudança proporcional no logaritmo do resultado $(\mathrm{Y})$. Nas variáveis independentes categóricas, o efeito é computado como uma mudança discreta em relação à categoria de referência. O efeito é estimado em termos relativos, em escala logarítmica, porém sem equivaler apropriadamente a uma alteraçáo percentual. A conversão da diferença proporcional em diferença percentual implica em calcular o exponencial do valor, aplicando-se a fórmula: $[\exp (\mathrm{Y})-1]{ }^{*} 100$. As duas escalas divergem crescentemente na medida em que o resultado em logaritmo aumenta.

Os valores dos gráficos estáo em escala logarítmica, pois o procedimento estatístico estimou a semielasticidade e o resultado foi estampado nos gráficos. A mesma métrica dos gráficos vai ser mantida no texto, por questão de ajuste. Uma diferença de 0,50 (.5 na forma em inglês do gráfico) significa que a renda da categoria designada (topo social, por exemplo) equivale à renda da categoria de referência (destituído) multiplicada por 1,649 (o exponencial); ou seja, a renda do grupo é $64,9 \%$ maior. Se a diferença original for negativa $(-0,5)$, o valor convertido em percentual decresce (equivale a $-39,3 \%$ ).

Os gráficos sáo apresentados com os intervalos de confiança de 95\%. Entretanto, não se deve usar somente o critério de sobreposição dos intervalos de confiança para definir se as estimativas diferem de forma significativa entre si. Esta aproximação útil pode levar a uma conclusão incorreta. Como regra geral, o exame da sobreposiçáo dos intervalores de confiança, em comparaçấo com o método padrão, rejeita a hipótese nula com menos frequência quando ela é verdadeira e, por outro lado, não rejeita a hipótese nula com mais frequência quando ela é falsa (Long e Freese, 2014, p. 297; Schenker e Gentleman, 2001). O comando de pós-estimação mlincom do Stata será usado para testar as diferenças ou mudanças de efeito no tempo e entre situaçóes, considerando a força das diferenças, os p-values e os intervalos de confiança (Long e Freese, 2014). Pode-se fazer uma interpretação abrangente de determinados resultados, que leve em conta os três aspectos simultaneamente, em particular quando se usam quatro interaçóes, que exigem mais casos para obter significância estatística.

São apresentadas estimativas desagregadas por gênero, como tem sido feito na literatura que diferencia as trajetórias de homens e mulheres. Assim, a comparação de gênero, em particular nos gráficos, diz respeito a padróes que emergem em cada universo de gênero, mantendo-se o foco da mobilidade social na relação entre origem e destino social. A comparação de gênero deve considerar que estáo sendo estimados, nos gráficos, efeitos proporcionais nos respectivos universos. As convergências e divergências entre os grupos no critério proporcional podem envolver padróes absolutos de renda diferentes para homens e mulheres. No tratamento das questōes de pesquisa, o desenho da investigaçẫo permitiu manter a análise de dados em um formato mais inteligível para o não especialista.

\section{Resultados e análises}

Primeira questão: existe uma associação direta entre origem de classe e recompensas de renda dos filhos além do efeito mediado pela educaçáo?

São apresentadas na Tabela 2 as rendas preditas em percentis selecionados no modelo básico (Efeito Total), no modelo com o controle adicional da educação dos filhos (Efeito Direto) e o percentual correspondente ao efeito direto da origem no efeito total. A descrição e a análise focalizam o efeito da origem de classe por gênero em diferentes níveis $\mathrm{da}$ distribuição da renda. Estimativas usando idade e idade ao quadrado, em vez de coorte, produzem resultados muito semelhantes.

Existe uma clara hierarquia de origem de classe na renda predita. As discrepâncias de origem são mais fortes nos níveis superiores da distribuição. Entre os homens, a renda predita da origem destituída representa nos percentis $\mathrm{P} 75$ e P90, respectivamente, somente $31 \%$ e $29,9 \%$ da renda da origem no topo social. Este padrão de classe é replicado também entre 
Tabela 2. Efeito da origem de classe em diferentes percentis da renda predita de todas as fontes em reais, total e direto, após o controle da educaçáo, por gênero. Brasil, PNAD 2014.

\begin{tabular}{|c|c|c|c|c|c|}
\hline Critério & Topo Social & Qual./Superv. & Pequ. Ativos & Trabalhador & Destituído \\
\hline & \multicolumn{5}{|c|}{ Homem } \\
\hline P25 Total & 1539 & 1163 & 807 & 1006 & 859 \\
\hline P25 Direto & 1462 & 1205 & 1001 & 1160 & 1055 \\
\hline P25 Direto \% & 95,0 & 104 & 124 & 115 & 117 \\
\hline P50 Total & 2911 & 1945 & 1164 & 1524 & 1205 \\
\hline P50 Direto & 2532 & 1938 & 1526 & 1733 & 1549 \\
\hline P50 Direto \% & 87,0 & 99,6 & 131 & 114 & 129 \\
\hline P75 Total & 6137 & 3658 & 1937 & 2530 & 1902 \\
\hline P75 Direto & 4473 & 3152 & 2416 & 2659 & 2399 \\
\hline P75 Direto \% & 72,9 & 86,2 & 125 & 105 & 126 \\
\hline P90 Total & 11017 & 7261 & 3319 & 4181 & 3289 \\
\hline P90 Direto & 7798 & 5462 & 3930 & 4115 & 3777 \\
\hline \multirow{2}{*}{ P90 Direto \% } & 70,8 & 75,2 & 118 & 98,4 & 115 \\
\hline & \multicolumn{5}{|c|}{ Mulher } \\
\hline P25 Total & 1085 & 1163 & 538 & 689 & 556 \\
\hline P25 Direto & 942 & 834 & 725 & 756 & 725 \\
\hline P25 Direto \% & 86,8 & 71,7 & 135 & 110 & 131 \\
\hline P50 Total & 2214 & 1485 & 916 & 1036 & 884 \\
\hline P50 Direto & 1503 & 1241 & 1158 & 1173 & 1148 \\
\hline P50 Direto \% & 67,9 & 83,6 & 126 & 113 & 130 \\
\hline P75 Total & 4329 & 2738 & 1465 & 1719 & 1411 \\
\hline P75 Direto & 2596 & 1980 & 1833 & 1851 & 1814 \\
\hline P75 Direto \% & 60,0 & 72,3 & 125 & 108 & 129 \\
\hline P90 Total & 8553 & 4937 & 2563 & 3117 & 2419 \\
\hline P90 Direto & 4227 & 3143 & 2912 & 2890 & 2892 \\
\hline P90 Direto \% & 49,4 & 63,7 & 114 & 92,7 & 120 \\
\hline
\end{tabular}

Fonte: Elaboração do autor com base nos microdados da PNAD 2014. Obs: o Efeito Direto \% foi calculado pela razão:

Direto/Total.

as mulheres. $\mathrm{O}$ resultado revela, por outro lado, que homens e mulheres não se beneficiam igualmente (ou sofrem ônus equivalentes) da mesma origem social. Entre as mulheres com origem no topo social, a renda predita nos percentis $\mathrm{P} 75$ e $\mathrm{P} 90$ representa, respectivamente, $70,5 \%$ e $77,6 \%$ da renda dos homens com a mesma origem. Quando procedem de origem no agrupamento destituído, as mulheres recebem somente $64,7 \%$ da renda dos homens, ao nível dos 25\% mais pobres (P25), e 74,2\% da renda, ao nível dos $25 \%$ mais ricos (P75).

$\mathrm{Na}$ origem no topo, entre os homens, a mediaçáo educacional representa uma parcela pequena, quando não bem pequena, da aquisição da renda atual. Entre as mulheres originárias do topo social, o efeito direto da origem é majoritário, embora em patamar menos forte, sendo que no percentil 90 (os 10\% mais ricos do grupo), fica no seu ponto mais baixo, pois equivale à metade do efeito total.

$\mathrm{Na}$ origem de empregado qualificado, a mediaçáo educacional importa para os homens somente nos dois níveis superiores à mediana. Neste grupo, o papel interveniente da educação responde por parte minoritária da renda das mulheres, porém está presente em todos os níveis da distribuiçẫo da renda. Nas demais origens de classe, por outro lado, quase sempre a renda predita com o controle da educação dos filhos é maior do que a renda total sem este controle. Entre estes grupos, o efeito da educação, em particular associado à distribuição deste fator, opera na direçâo contrária 
do efeito de origem: a renda aumenta com a remoção estatística desta desvantagem que "comprimia" o efeito de origem. Estas estimativas revelam qual seria a renda hipotética se a origem nấo estivesse associada a desvantagens na aquisição da educação. Para estes grupos, a renda dos filhos poderia ser um tanto melhor sem este componente de "mediação negativa" associado à origem social. A principal variação de gênero nos padrōes de associação diz respeito ao fato da vantagem de origem ser menor, e do ônus de origem ser maior, para a mulher. Isto sinaliza que fatores associados ao gênero estariam afetando a conversão do efeito de origem em resultados no destino.

Segunda questão: a associação intergeracional líquida, ou seja, o efeito direto da origem, após controle da educação, declinou no tempo entre as coortes?

A análise é conduzida confrontando-se a evolução do efeito total da origem de classe (Gráfico 1) e do efeito direto da origem (Gráfico 2) na renda. Foram estimados termos interativos entre origem de classe, coorte e gênero. São consideradas quatro coortes em intervalos de dez anos. Na base do gráfico, "48-57" representa os nascidos de 1948 a 1957, e assim por diante. Estimam-se mudanças proporcionais na renda, a depender da origem de classe. A linha onde está o valor zero indica ausência de diferença em relação à origem no agrupamento destituído. Será destacado o contraste entre a origem no topo social e no agrupamento destituído, com ênfase na evolução entre a primeira e a última coorte. Nos comentários dos gráficos, resultados incertos vão ser marcados com o asterisco (P90*) ou referidos no texto. IC será a abreviatura de intervalo de confiança. O fato da primeira e da última coorte estarem justapostas verticalmente no gráfico, em cada categoria de gênero, facilita a visualização da trajetória. O uso de interaçôes entre origem e coorte representa um procedimento crítico no estudo, pois visa justamente avaliar o comportamento do efeito na sucessão de coortes. Este pode variar em cada coorte, e o processo indicar ou não uma tendência histórica. Pode revelar eventualmente uma flutuação sem tendência ou direção certa, o que representa, em certo sentido, uma reproduçáo ou continuidade de longa data do padráo histórico do passado.

No universo feminino, as origens no topo social, no empregado qualificado e no trabalhador típico,

Gráfico 1. Diferença proporcional de renda (Efeito Total) da origem de classe em relaçáo ao destituído, em diferentes níveis da distribuição, por gênero e coorte, com intervalo de confiança de $95 \%$.

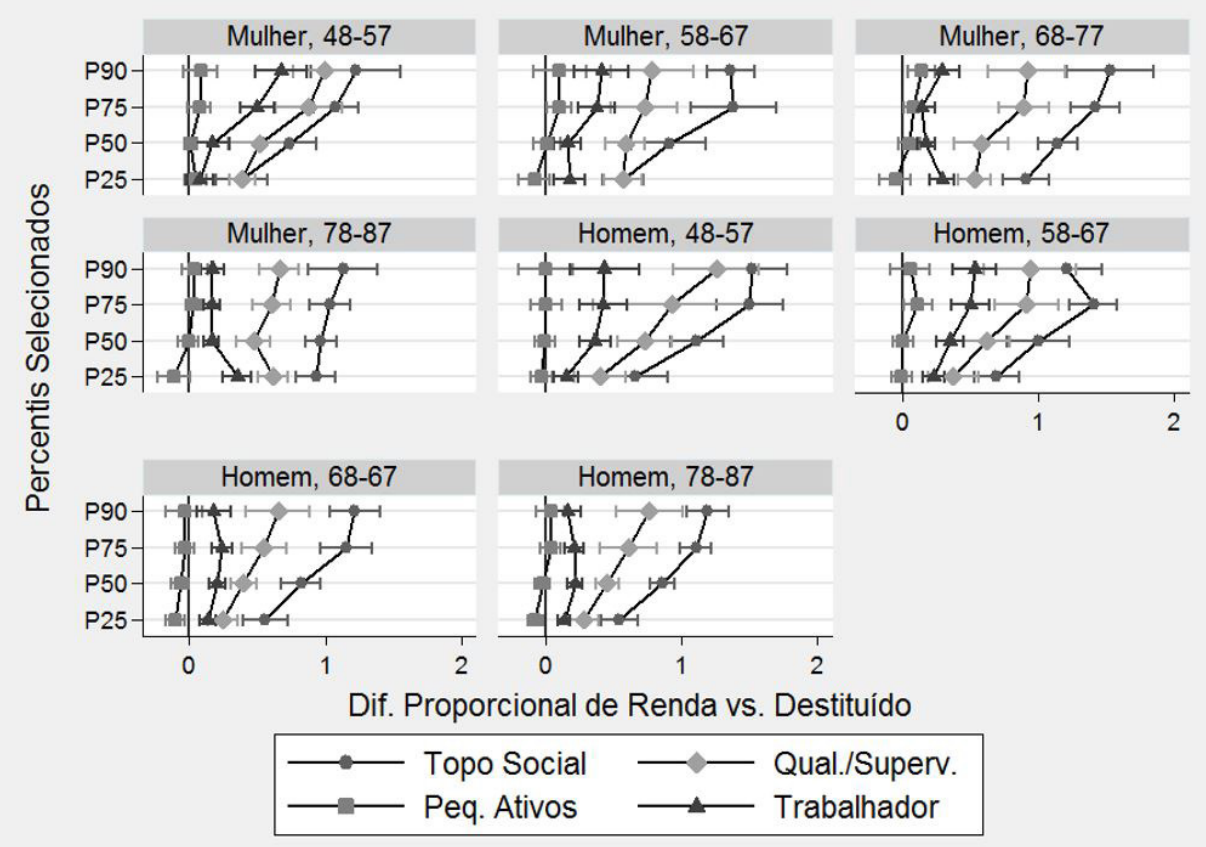

Fonte: Elaboração do autor com base nos microdados da PNAD 2014. 
Gráfico 2. Diferença proporcional de renda (Efeito Direto) da origem de classe em relação ao destituído, em diferentes níveis da distribuiçáo, por gênero e coorte, com intervalo de confiança de $95 \%$.

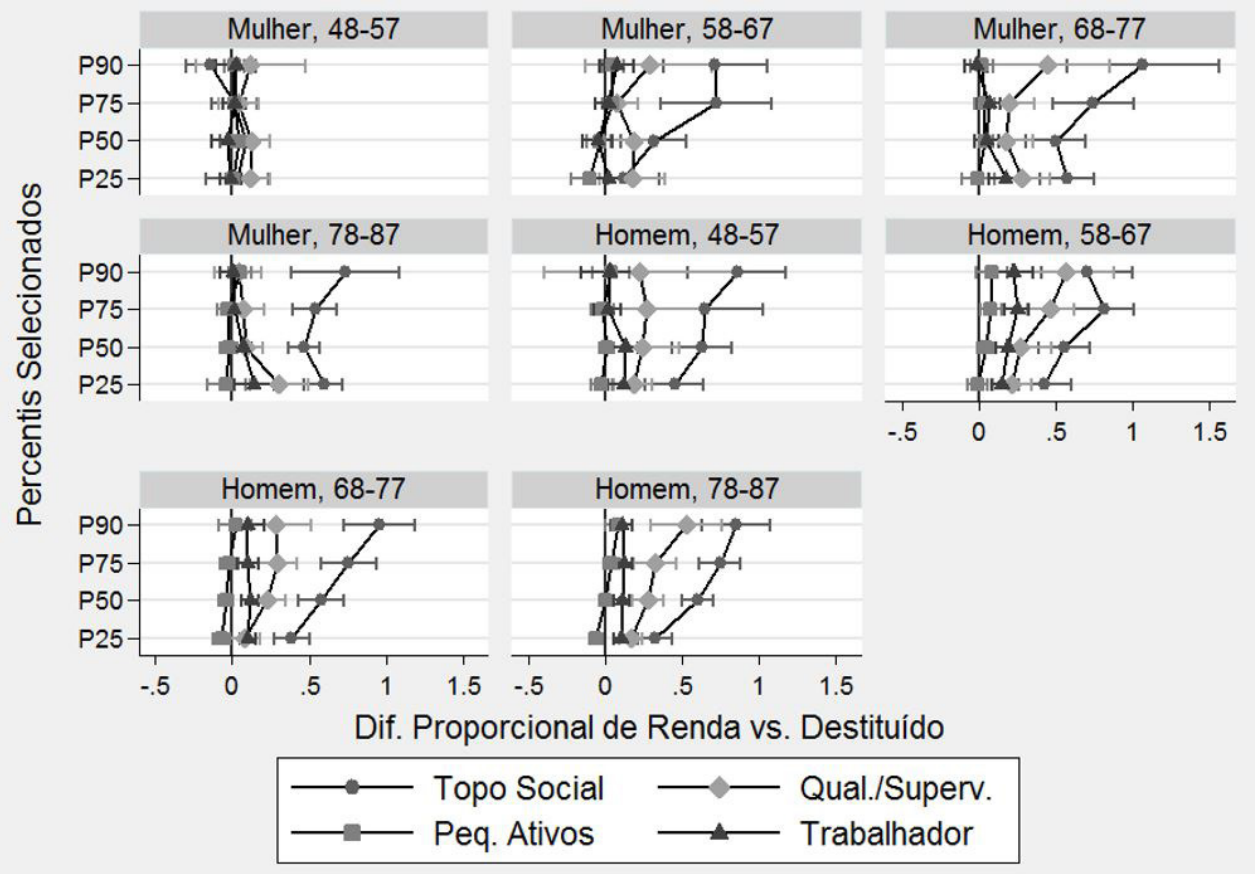

Fonte: Elaboração do autor com base nos microdados da PNAD 2014.

mostram vantagens ponderáveis ou expressivas em relação ao destituído (Gráfico 1). As vantagens são especialmente fortes para as origens no topo e em emprego qualificado nos níveis superiores da distribuição. Entretanto, na primeira coorte em particular, a vantagem da origem de classe no topo para a mulher é inferior à dos homens. Na sucessão de coortes, a vantagem da origem no topo aumenta $(+0,23)$ ao nível da mediana, embora se mantenha perto do limite da significância estatística, e se eleva em especial em P25 (+0,542). Nos níveis superiores da distribuição, não é certo que tenha havido uma retração da vantagem de classe no topo social. Nas duas coortes intermediárias ocorreu aumento temporal expressivo da vantagem de origem. $\mathrm{Na}$ origem de empregado qualificado, por sua vez, o resultado é mais misto. Ocorre aumento da vantagem em P25, mudança incerta em P50* (mediana), aumento da diferença em P75 $(+0,204)$ e redução em P90 $(-0,331)$.

Entre os homens (Gráfico 1) ocorre uma redução do efeito total da origem no topo nos quatro níveis da distribuição. Embora, como regra geral, os intervalos de confiança sejam elevados, esta mudança é confirmada com o uso do comando mlincom, exceto no caso de $\mathrm{P} 25^{*}$, que não seria estatisticamente significativa. Foi registrada em P75 a maior retraçáo em termos absolutos, da ordem de $-0,397$, pois a vantagem da origem no topo social cai de 1,502 para 1,105. A vantagem de origem de empregado qualificado sofre retração similar. Em P90 se dá a maior retração, da ordem de -0,491. O fato da mulher de origem no topo social ter ampliado ou mantido forte sua vantagem de renda, enquanto a do homem caiu, indica que o grau de desigualdade de origem entre as mulheres foi ficando mais próximo do que se verifica entre os homens, quando vistos nos respectivos universos de gênero. $\mathrm{Na}$ medida em que as mulheres ingressam diretamente na ordem de classe, como vem ocorrendo no país, elas se tornam mais desiguais entre si, na comparação das rendas pessoais.

As trajetórias divergentes de gênero se fundem na média dos casos para gerar um padrão populacional. Deve ser levando em conta que homens e mulheres estão distribuídos de modo aproximadamente equivalente entre os descendentes, pois o levantamento de dados de mobilidade social seleciona aleatoriamente um 
membro do domicílio. Estimativas à parte, agregadas, sem separação por gênero, mas com controles e interaçóes iguais, revelam um aumento da vantagem de origem no topo em P25, uma manutenção de vantagem em $\mathrm{P} 50^{*}$, uma diminuição de vantagem em P75 (-0,222; IC de -0,403 a -0,041) e uma provável redução em $\mathrm{P} 0^{*}(-0,208$; IC de $-0,469$ a $+0,053)$. Uma inflexão descendente na trajetória nos níveis superiores da distribuição, caso tenha ocorrido também em P90*, não afetou as coortes intermediárias, pois se concentrou na última coorte. A origem no topo social, ainda assim, mantém nesta coorte vantagem de 1,071 em P75 e de 1,163 em P90. Convertendo para percentuais, a renda dos filhos do topo excede, respectivamente, em 192\% e em $220 \%$ a renda esperada da origem destituída. Nestes níveis de renda, além disso, o contraste do topo é feito com um grupo proporcionalmente menor $(5,2 \%)$ de origem destituída e provavelmente mais seletivo em atributos positivos.

O efeito direto da origem foi estimado recorrendo-se a uma interação tripla entre origem, coorte e gênero (Gráfico 2). Ao remover o constrangimento de efeitos equivalentes, com a introduçáo de termos interativos, permite-se que o efeito de origem varie por coorte e gênero, e vice-versa. Além disso, não se introduz somente o controle simples da educação dos filhos, pois foi adicionado ao modelo um termo interativo entre coorte e educação. Isto significa que o efeito da educação pode variar por coorte. Esta opçáo leva em consideração que tanto a distribuição da educação quanto os retornos de renda da educaçáo podem se alterar entre as coortes.

$\mathrm{Na}$ origem no topo social, as estimativas para o homem (Gráfico 2) não confirmam uma alteração do efeito direto entre a primeira e a última coorte nos quatro níveis da distribuição da renda. Foram registradas diferenças no tempo de $-0,130 \mathrm{em} \mathrm{P25*}$, $-0,025$ em P50* $+0,096$ em P75* e -0,005 em P90*. As alteraçóes são pequenas, não são estatisticamente significativas, e os intervalos de confiança (IC) são muito elevados. Não é certo, então, que tenha havido retração do efeito direto para a origem no topo. Note-se que estamos falando de mudanças no tempo, apuradas pelo comando mlincom do Stata, e não do que se passa com as estimativas pontuais em cada coorte. Em cada percentil, as flutuaçóes entre as quatro coortes registram diferenças a favor da origem no topo em patamares relativamente próximos. $\mathrm{Na}$ origem de empregado qualificado ocorreu processo similar, exceto em P90*; neste nível há aumento de 0,302 (IC de -0,355 a +0,959). Não é certo que tenha havido diminuiçóes das vantagens relativas nesta origem.

Os resultados para a mulher (Gráfico 2) revelam uma diferença marcante em relação ao homem, em particular na primeira coorte, na qual inexistem diferenças estatisticamente significativas entre as origens no efeito direto. Deve ser observado o montante do efeito total, retratado no Gráfico 1, para entender adequadamente este quadro aparentemente paradoxal. Os efeitos de origem para a mulher, embora sejam marcantes na primeira coorte, seriam integralmente mediados pela realização educacional. Este fato singular torna todas as mudanças entre a primeira e a última coorte fortes e estatisticamente significativas. $\mathrm{O}$ mais importante é constatar que, para a origem no topo, esta situação se altera nas coortes seguintes. A partir da segunda, a vantagem direta da origem no topo, como regra geral, persiste no tempo. Merece destaque, por outro lado, o que se passa com a origem de empregado qualificado. A partir da mediana, as diferenças de origem, inicialmente pequenas, diminuem no tempo; as alteraçoos, contudo, não são estatisticamente significativas. Isto significa que, na comparação com a origem no agrupamento destituído, a mediação educacional se impõe na disputa pelas rendas mais altas a partir da origem empregado qualificado.

Entre homens e mulheres, não é certo que tenham se reduzido os efeitos diretos da origem privilegiada. Gênero importa ao se associar a patamares muito diferenciados dos resultados. Além disso, para as mulheres na origem abaixo do topo existe grande dependência da mediaçấo educacional, o que não é o caso da origem de empregado qualificado para o homem. Para os homens, o efeito direto de origem é mais forte, ou seja, a trajetória é menos dependente da mediação educacional. Isto significa que processos que afetam o valor da educação podem impactar mais na mobilidade social da mulher. 
Os processos diferenciados de gênero se misturam para formar uma tendência populacional majoritária. Estimativas especiais à parte, sem separação por gênero, mas com o mesmo modelo interativo, mostram que o efeito direto da origem no topo aumentou em todos os níveis da distribuição. Os aumentos entre a primeira e a última coortes foram de 0,202 em P25, 0,168 em P50, 0,298 em P75 e 0,409 em P90. As diferenças a partir da mediana se expandem já nas coortes intermediárias. $\mathrm{O}$ resultado final positivo de longo prazo envolveu um pequeno recuo na última coorte.

Um problema subjacente deve ser considerado para se chegar a uma conclusão final sobre este ponto. $\mathrm{Na}$ análise da evolução do efeito direto da origem de classe entre as coortes, a comparação com o destituído (ou o trabalhador, ou ambos) gera um problema. Estariam sendo comparados resultados que possuem significados diferentes, pois o controle não tem a mesma implicação, nem atua na mesma direção, de forma indistinta, para todas as origens de classe, embora estejamos removendo, em todos os casos, as diferenças na distribuição e no potencial causal da educação no resultado final. A renda predita com o controle da educação, visando captar o efeito direto da origem, representa a renda hipotética que a categoria da base social teria caso esta origem não estivesse associada à desvantagem educacional dos filhos, como foi visto na análise da Tabela 2 . Para a origem no topo, o significado do controle é diferente, pois ele representa a renda predita caso a vantagem educacional dos filhos fosse removida, ou seja, corresponde à contribuição interveniente da educação para a vantagem de renda. Este modo padrão ou consagrado de estimar o efeito direto da origem - quando o controle da educação tem implicaçóes claramente opostas - pode estar subestimando as diferenças no efeito direto entre o topo e a base da estrutura social. Aceito este argumento, o efeito direto da origem no topo poderia ser maior do que está sendo medido.

Terceira questão: a associação intergeracional varia por níveis de escolaridade ou, de modo mais específico, o efeito da origem social na renda dos filhos é menor entre os indivíduos mais educados?

O Gráfico 3 contrasta as origens no topo social e de empregado qualificado com o bloco das demais origens, cujos filhos têm renda tipicamente inferior (pequenos ativos, trabalhador típico e destituído). Três fatores informaram a escolha deste contraste. Foram conjugados os critérios de realizar uma comparação com elevado peso demográfico, o foco nos dois agrupamentos que expressam vantagens de origem, e a representação gráfica mais limpa, em função do uso de intervalos de confiança, já que as diferenças entre os grupos agregados na comparação eram menores. Estimou-se uma interação tripla entre origem, educação e gênero. $\mathrm{O}$ efeito condicional da origem pode variar simultaneamente por nível educacional e gênero. $\mathrm{O}$ valor zero na linha que corta o gráfico indica o limiar de ausência de diferença em relação ao bloco de referência. Isso não significa que basta ver se o intervalo de confiança de um grupo cruza a linha.

No gráfico, a categoria Fundamental agrega médio incompleto, fundamental ou menos; Médio representa médio completo ou superior incompleto; e Superior completo é o que diz. A relação focal é entre origem de classe e renda dos filhos. A educação e o gênero representam contextos ou fatores moderadores que podem alterar esta relação, acentuando-a ou atenuando-a, pois são usadas interaçóes entre elas e a origem de classe. A abordagem adotada não implica em desconhecer o caráter simétrico dos efeitos interativos (Kam e Franzese, 2007, p. 16). Isto significa que seria possível uma interpretaçáo invertida que colocasse a origem social como fator moderador. Desembaralhar as duas interpretaçóes em termos causais demandaria testar mecanismos específicos subjacentes às interações (Fiel, 2020, p. 355). ${ }^{2}$

As vantagens de origem de classe no topo social são marcantes nos níveis maiores de educação. No superior completo, a vantagem de classe é de 0,424 para a mulher e de 0,499 para o homem em P50; e, respectivamente, de 0,518 e 0,484 em P75 e de 0,561 e 0,392 em P90. Este padrão observado já compromete a ideia de que a aquisição de educação mais elevada, em particular ao nível superior, seria um fator nivelador ou redutor das diferenças de origem. A caracterização inequívoca desta questão pode ser complementada pelo conhecimento das diferenças de segunda ordem, ou seja, as diferenças entre níveis educacionais nas diferenças de origem de classe. 
Gráfico 3. Diferença proporcional de renda da origem de classe com vantagens em relaçáo ao agrupamento inferior, em diferentes níveis da distribuição, por gênero e nível educacional, com intervalo de confiança de $95 \%$.

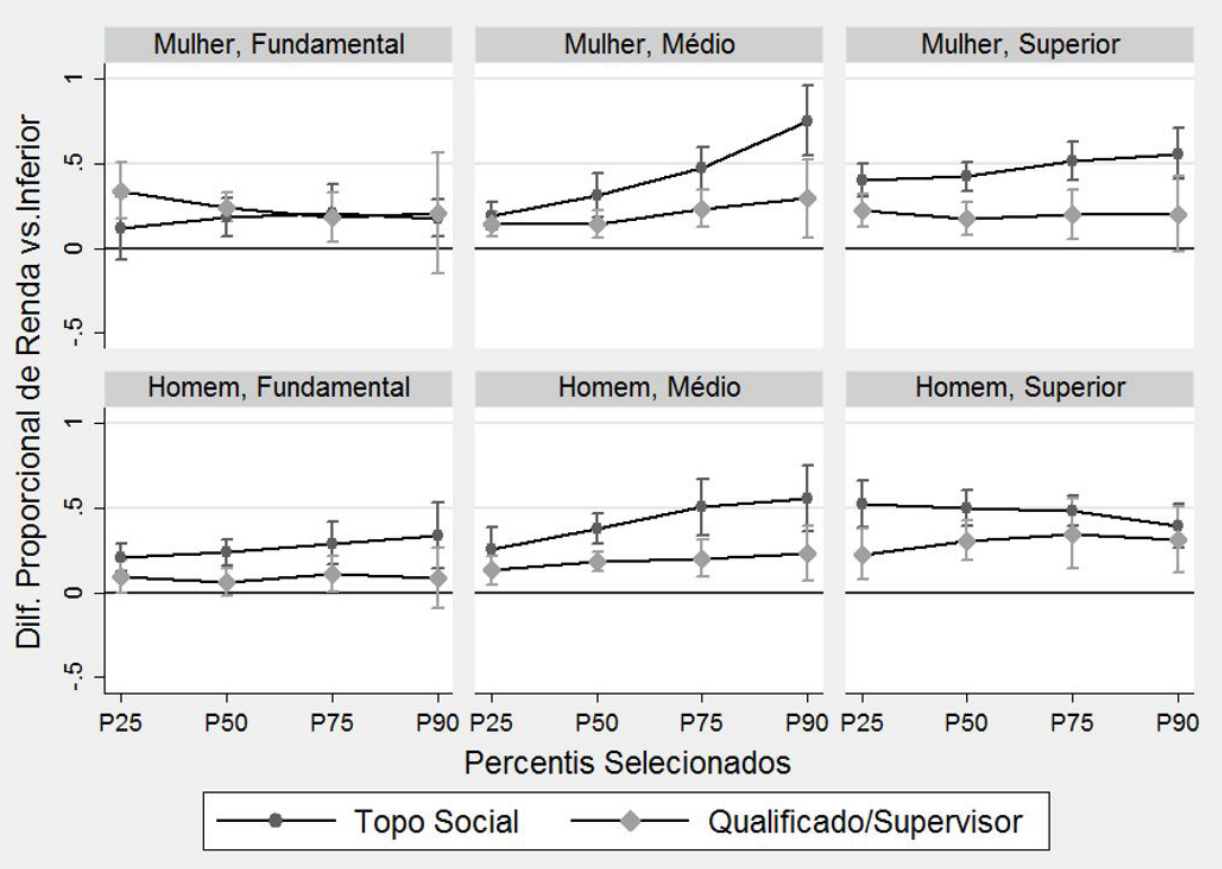

Fonte: Elaboração do autor com base nos microdados da PNAD 2014.

Para a origem no topo social, todas as diferenças de classe no Superior Completo, em relação ao nível Fundamental, são ponderáveis e têm significância estatística no universo feminino. As diferenças são de 0,285 em P25, de 0,240 em P50, de 0,311 em P75 e de 0,385 em P90. Estes resultados não confirmam a noção de que o efeito de origem poderia ser menor ao nível do ensino Superior Completo. Por outro lado, a origem de classe no topo, em quase todos os níveis de renda, exceto talvez em P25* (IC de $-0,068 \mathrm{a}+0,307)$, gera uma vantagem de renda em quem atinge somente o Fundamental. A tese da vantagem compensatória é confirmada nos níveis de renda acima de P25, que mais importam para quem vem de uma origem privilegiada.

No Superior Completo, em comparação ao Fundamental, as diferenças de segunda ordem no universo masculino são de 0,316 em P25, de 0,261 em P50, de 0,195 em P75 e somente de 0,054 em P90* (IC de -0,179 a +0,287). O último resultado não é estatisticamente significativo. $\mathrm{O}$ quadro pode refletir uma conjunção seletiva entre situaçôes e atributos.
A vantagem da origem no topo social, neste contexto, pode nâo ter sido suficiente para sobrepujar outro tipo de seletividade não baseada em origem. Entretanto, estimativa à parte, para o conjunto dos casos, sem a desagregação por gênero, mostra em P90 uma diferença de 0,218 , estatisticamente significativa, a favor da origem no topo social (IC de $+0,066$ a $+0,369$ ). As evidências indicam que a educação superior não representa um domínio capaz de nivelar ou mesmo restringir de forma ponderável as discrepâncias de origem social. Por outro lado, na origem no topo, a vantagem de renda de quem fracassa na escola é expressiva em todos os níveis de renda. Varia de 0,2087 em P25 a 0,338 em P90. Na transposição para percentual, excede o agrupamento inferior de $23,3 \%$ a $40,2 \%$. Isto significa que a origem no topo gera, no universo masculino, um apreciável benefício compensatório para quem não conseguiu converter a origem privilegiada em melhor aquisição educacional. De um lado, os recursos associados à origem privilegiada podem ser mobilizados para superar ou minimizar um resultado negativo precedente. De outro lado, 
quando a posição de origem já é baixa, de modo que o evento negativo não implica em rebaixamento social, há menos incentivos para empregar os poucos recursos disponíveis em um empreendimento mais incerto (Bernardi, 2014, p.76).

A comparação de gênero revela que, para o homem, a vantagem compensatória da origem no topo social é maior quando se está limitado ao ensino Fundamental (médio incompleto ou inferior). Nesta situação de déficit educacional, o homem possivelmente conta com meios não educacionais associados à origem para proteger sua renda. Por outro lado, o ensino Superior Completo incrementa mais a renda da mulher quando homens e mulheres têm origem no topo social, nos níveis superiores da distribuiçáo da renda. Quando adquire este nível de escolaridade, a mulher também está melhor do que outra mulher de origem social inferior; ou seja, a distância de renda entre origens de classe fica maior. Esta melhor situação em relaçẫo ao homem diz respeito, neste caso, à força adquirida pelo condicionamento de origem de classe no universo feminino.

Quarta questão: a associação entre a educação dos indivíduos e as recompensas de renda tem variado entre as coortes, ou seja, os retornos econômicos da educação têm aumentado ou diminuído no tempo?

No Gráfico 4 são estimadas as diferenças proporcionais na renda, por níveis educacionais, entre as coortes. O modelo estima interaçōes entre coorte, educação e gênero. Controla adicionalmente pela origem de classe, visando captar melhor, ou de forma mais pura, sem superposiçôes de efeitos, as mudanças genuínas nos retornos da educação entre coortes. $\mathrm{O}$ fato de a primeira e a última coorte estarem justapostas verticalmente no gráfico facilita a visualização da trajetória.

No universo feminino os retornos proporcionais da educação superior completa caem da primeira à última coorte em níveis maiores de renda. A redução é de $-0,345$ em P75, e de $-0,413$ em P90. A alteração de $-0,106$ em P50* (IC de $-0,241$ a $+0,028$ ) penderia para a redução. Em P25, o retorno feminino aumenta. Os retornos da educação média, por sua vez, têm aumento em P25, alteração indefinida em P50* e queda expressiva em P75 $(-0,332)$ e P90 $(-0,600)$. Os decréscimos de retornos nos níveis superiores da distribuição foram paulatinos na sucessão das coortes.

\section{Gráfico 4. Diferença proporcional de renda entre níveis educacionais, em diferentes níveis da distribuiçáo da renda, por gênero e coorte, com intervalo de confiança de $\mathbf{9 5 \%}$.}

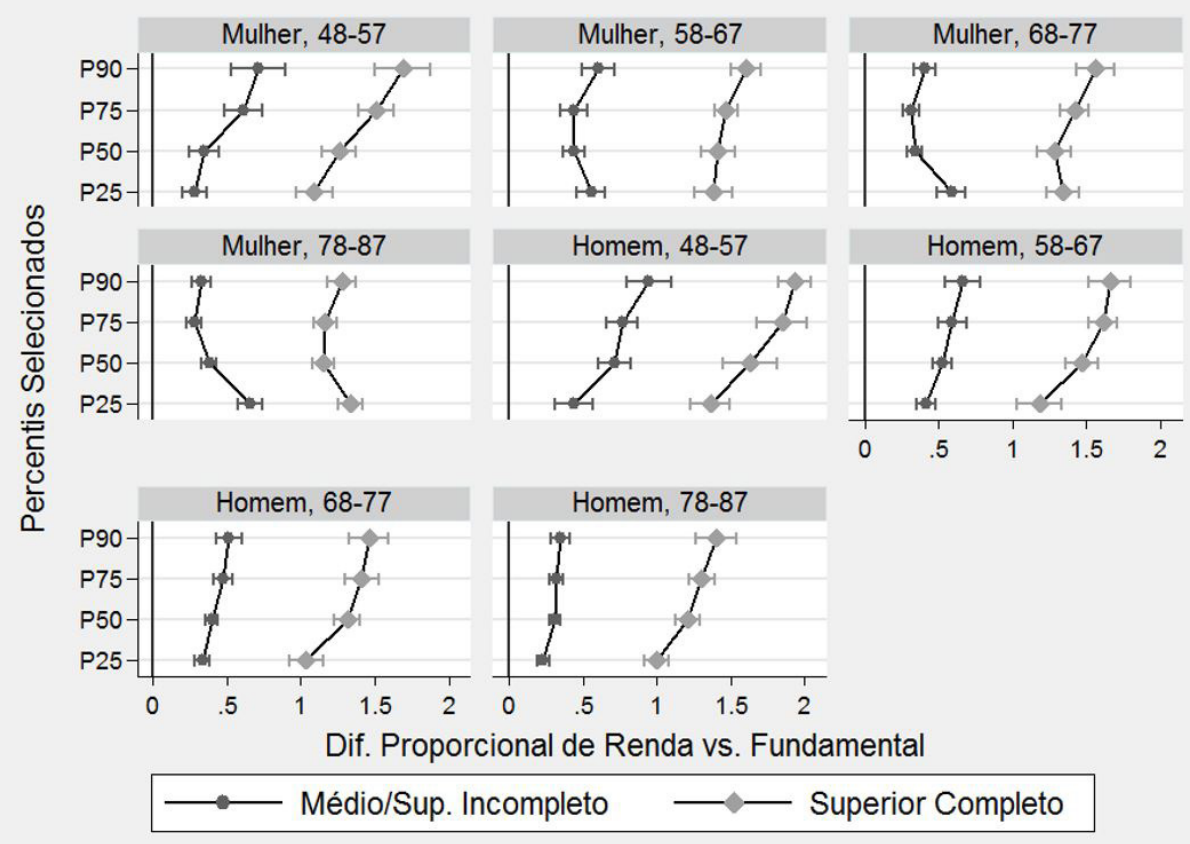

Fonte: Elaboração do autor com base nos microdados da PNAD 2014. 
No universo masculino, em todos os níveis da distribuição de renda, os retornos proporcionais da educação superior completa tiveram queda maior. A redução foi de -0,364 em P25, -0,424 em P50, -0,545 em P75 e -0,532 em P90. Também em todos os níveis, o processo se deu de forma progressiva no transcurso das coortes. Um desdobramento regressivo bem similar ocorreu com os retornos da educação média. Todas estas alteraçóes foram estaticamente significativas. Na última coorte, os retornos de renda dentro do grupo masculino da educação superior ainda ultrapassam os retornos da mulher em P75 (+0,140); já as diferenças de gênero em P50 e P90 não são estaticamente significativas.

A queda dos retornos da educação superior entre as mulheres, cuja distribuição favorece o grupo, pode estar associada à expansão ocupacional insuficiente e segregada, em um quadro de elevação geral da escolaridade no grupo e/ou de maior oferta de escolaridade superior entre as mulheres. As retraçóes nas discrepâncias de gênero em retornos de renda da educação superior podem estar associadas a mudanças na combinação entre educação superior e poder profissional-gerencial no mercado de trabalho. O esclarecimento das causas das mudanças, no entanto, demandaria investigação adicional.

$\mathrm{Na}$ parte final da descrição e análise, os retornos de renda da educação vão ser estimados por origem de classe, coorte e gênero (Gráficos 5 e 6). O modelo recorre a uma interação simultânea de quatro variáveis: origem de classe, coorte, educação e gênero. Os efeitos interativos removem o constrangimento estabelecido pelo modelo de efeitos aditivos ou equivalentes entre as diferentes origens, níveis educacionais e as duas categorias de gênero. Os efeitos podem variar para mais ou para menos nas diferentes combinaçôes entre contextos. Serão focalizados aqui somente os gráficos relativos aos polos da estrutura social de origem, ou seja, a origem no topo social e no agrupamento destituído. Leve-se em conta que a comparação original está sendo feita dentro da própria origem comum. Comparamse pais com origens iguais, porém filhos com níveis diferentes de educação. Os contrastes entre diferentes origens podem ser feitos, pois estão sendo usadas as diferenças proporcionais na renda. A métrica não é distorcida pelos níveis diferenciados de renda entre os

Gráfico 5. Diferença proporcional de renda entre níveis educacionais para a origem de classe no topo social, em diferentes níveis da distribuiçáo da renda, por gênero e coorte, com intervalo de confiança de 95\%.

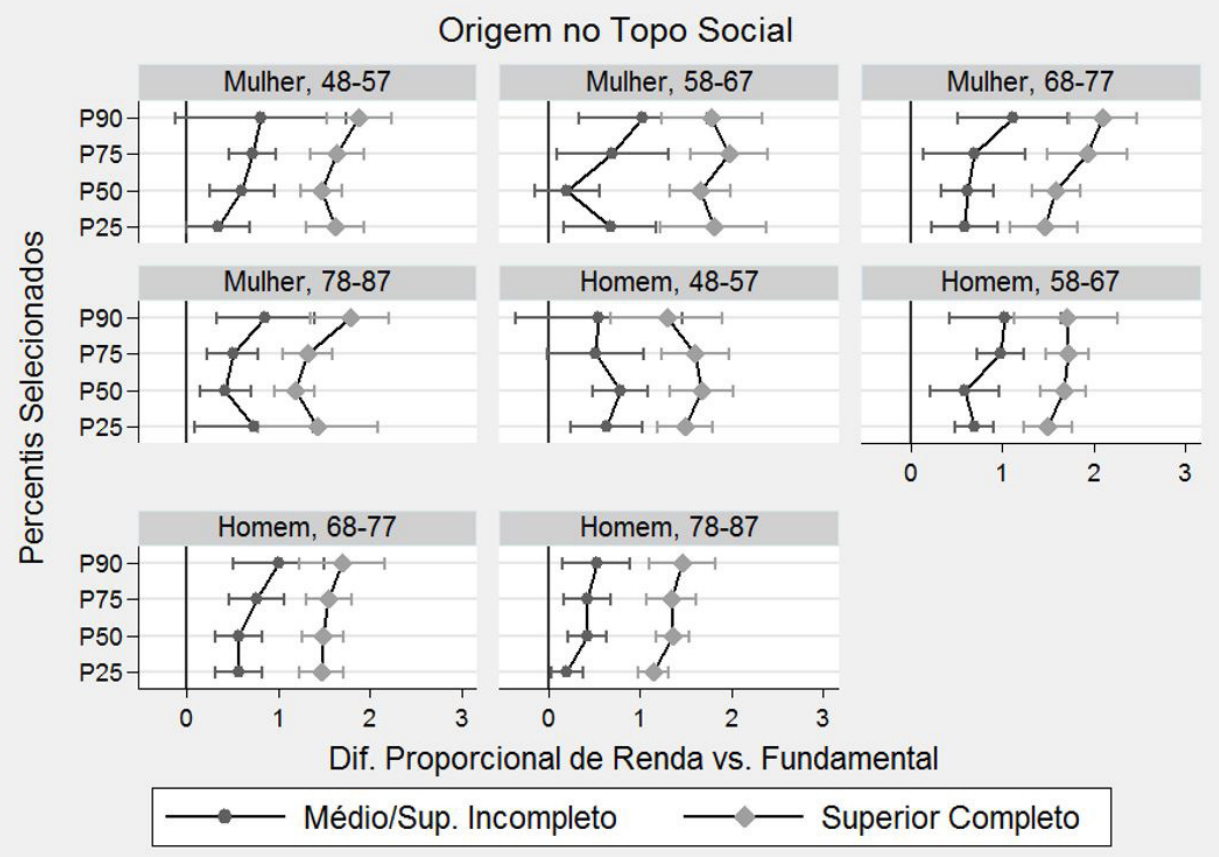

Fonte: Elaboração do autor com base nos microdados da PNAD 2014. 
Gráfico 6. Diferença proporcional de renda entre níveis educacionais para a origem de classe no grupo destituído, em diferentes níveis da distribuiçáo da renda, por gênero e coorte, com intervalo de confiança de $95 \%$.

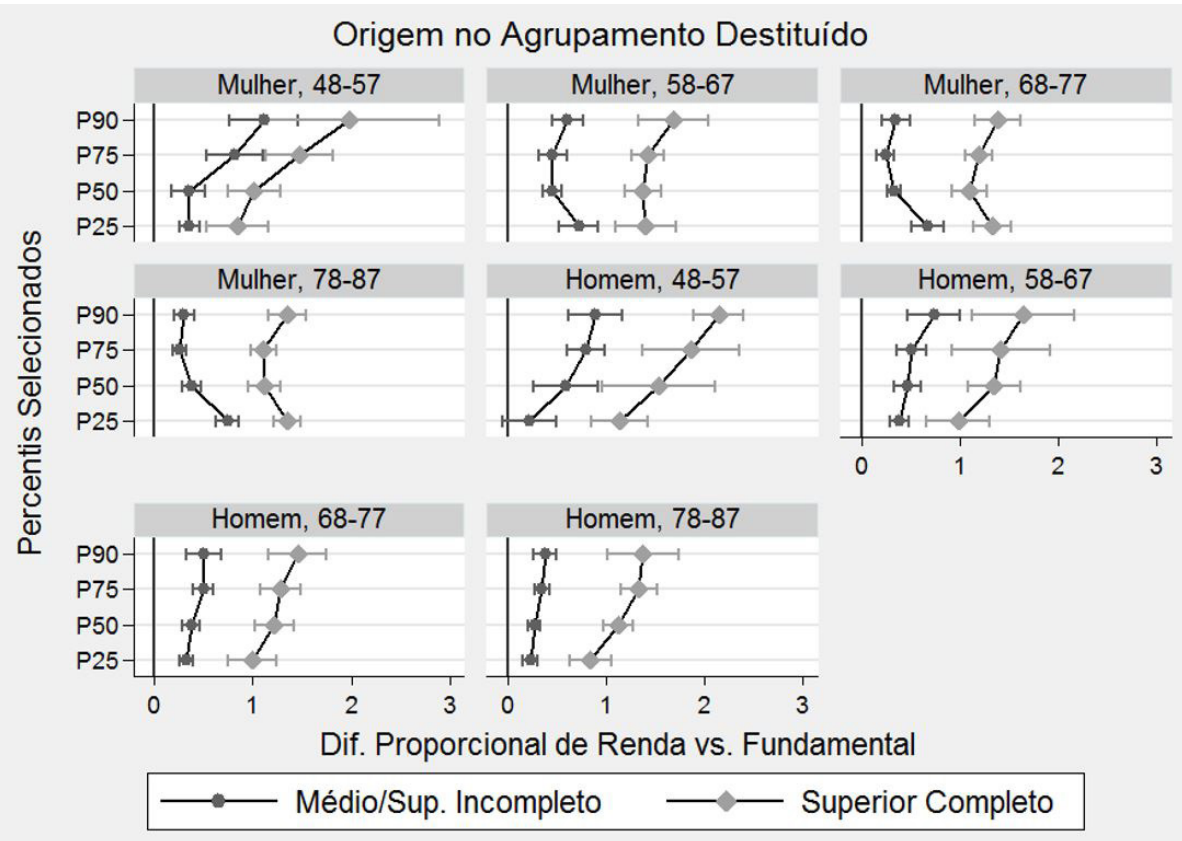

Fonte: Elaboração do autor com base nos microdados da PNAD 2014.

grupos. Esta métrica tampouco é contaminada pelos distintos perfis de idade-renda associados às coortes. A relação focal é entre nível educacional e renda dos filhos; as demais variáveis no gráfico representam os contextos que podem alterar esta relação, ou seja, acentuá-la ou atenuá-la, pois são usadas interações entre eles e o nível educacional. Os cruzamentos e interaçôes entre as categorias de quatro variáveis, nesta situação, podem simplesmente não oferecer casos suficientes para detectar associaçóes existentes com uma precisão aceitável. Neste contexto, pode ser melhor priorizar a detecção de tendências, e não visar tanto um padrão convencional de significância estatística.

A trajetória dos efeitos de origem pode ser bem visualizada, pois a primeira e a última coorte de ambos os gêneros estão verticalmente justapostas (Gráfico 5). No universo masculino os retornos proporcionais da educação superior completa, para a origem no topo social, se reduziram em P25, P50 e P75*. Uma interpretação abrangente da redução em P75* $(-0,264)$ e do aumento em P90* $(+0,164)$ sugere que não é certo (em especial em P90) que os retornos caíram. $\mathrm{Na}$ coorte mais recente, as vantagens de retornos se mantiveram bem altas em P75 $(1,335)$ e P90 $(1,454)$. Para a origem no topo, os retornos da educação média, por sua vez, caíram entre a primeira e a última coorte. A queda entre as coortes foi paulatina em P25 e P50. Entretanto, as alteraçóes em P75* $(-0,084)$ e em P90* $(-0,022)$, além de pequenas e sem significância estatística, foram precedidas de forte aumento dos retornos da educação nas coortes intermediárias. $\mathrm{O}$ resultado final de longo prazo sinaliza, para estes níveis da distribuição, uma flutuação sem tendência clara no conjunto do período.

No universo feminino os retornos proporcionais da educação superior completa, para a origem no topo social, registram quedas nos níveis de renda até P75. De forma geral, esta queda se concentrou na última coorte, já que ocorreram aumentos dos retornos nas coortes intermediárias. As mudanças entre a primeira e a última coorte não são estatisticamente significativas, mas os intervalos de confiança pendem fortemente para o valor negativo em P50* e P75*. A queda em $\mathrm{P} 0^{*}$ seria mais incerta, pois a redução foi 
somente de $-0,097$ (IC de $-0,652 \mathrm{a}+0,458$ ). Ao final deste jogo de tendências dentro de cada universo de gênero, na última coorte o retorno (interno ao grupo) da mulher é superior ao homem em P25*, inferior em P50*, equivalente em $\mathrm{P} 75^{*}$ e superior em P90*. Considerando a significância estatística, não é certo que haja diferenças entre os dois. Os retornos da educação média, por outro lado, aumentaram bastante em P25* e um pouco em P90*, ou seja, nos extremos da distribuição. Houve reduçóes dos retornos em P50* e P75*. Contudo, não são alteraçôes estatisticamente significativas e possuem intervalos de confiança elevados, o que as torna incertas.

A comparação de gênero a respeito dos retornos da educação superior para a origem no topo social mostra que homens e mulheres preservaram ganhos ao nível superior da distribuição (P90). Na última coorte prevalece o equilíbrio de gênero, ou vantagem para as mulheres nos níveis superiores. $\mathrm{O}$ que isto diz sobre a interação entre gênero e origem de classe? No primeiro caso, a origem importa conjuntamente para preservar os retornos da educação superior; no segundo, os retornos proporcionais são mais desiguais entre as mulheres, ou melhor, voltam ao nível de desigualdade da primeira coorte. O contraste educacional revela que, para a mulher, na comparação entre pares, quem vem de uma origem privilegiada tem mais a perder (ou menos a reter) quando náo atinge a escolaridade superior.

Aborda-se agora o que acontece aos retornos da educação superior completa, na sucessão das coortes, para a origem no agrupamento destituído (Gráfico 6). É interessante observar que os retornos são altos na métrica de diferenças proporcionais. A razão disto prende-se ao fato de a educação superior completa estar sendo contrastada com a educação fundamental entre os pares que procedem desta origem. Os que vieram do agrupamento destituído e adquiriram tal nível educacional representam um subgrupo pequeno $(8,4 \%)$ e seletivo. Além disto, esta origem, em geral, não provê outros recursos que possam compensar um déficit educacional. A questão a ser esclarecida diz respeito às mudanças no "valor" da educação - no transcurso das coortes e condicionadas por determinada origem - para propiciar ganhos ou vantagens de renda aos filhos.
O Gráfico 6 mostra como as interaçóes entre origem destituída, coorte, educação e gênero têm afetado os retornos da educação para o homem. Os retornos da educaçấo superior decrescem em todos os níveis de renda. Os decréscimos absolutos mais fortes, com significância estatística convencional, ocorrem em P75 $(-0,530)$ e P90 $(-0,769)$. Este nível de queda reflete, em parte, o fato de a amplitude das vantagens (a perder) ser maior em P90. As mudanças nestes níveis são estatisticamente significativas. A queda dos retornos é um processo histórico, constante e progressivo na sucessão das coortes. Não diz respeito à última coorte em especial. Partindo-se desta origem, por outro lado, as vantagens de adquirir ensino médio completo ou superior incompleto, em relação à educação abaixo deste patamar, caíram pela metade ou mais em quase todos os níveis de renda. Os retornos da educação média têm uma importância especial para quem vem do agrupamento destituído, pois é uma realização mais factível, que envolve uma parcela mais representativa dessa origem. Equivalem a $29,7 \%$ no conjunto das coortes e a $41,5 \%$ na última coorte. Entre a primeira e a última coorte, a vantagem em P50 cai de 0,591 para 0,271; em P75 cai de 0,790 para 0,346 ; em $\mathrm{P} 90$ cai de 0,888 para 0,378 . São mudanças estatisticamente significativas. Em P25* a modesta vantagem de hoje $(0,228)$ é quase a mesma da primeira coorte $(0,217)$, diferença ínfima que sinaliza não alteração. Esta perda relativa não é devida a uma elevaçáo do valor da educação fundamental, com a qual está sendo contrastada, pois cada vez mais pessoas têm acesso ao nível abaixo do médio. Decorre do fato de se obter menos do mesmo patamar. Esta interpretação é confirmada pelo exame das rendas preditas, que mostra que, a partir da mediana, as diferenças estáo associadas a alteraçôes negativas mais fortes na educação média. Constata-se, por fim, que a depreciação do valor da educaçâo média foi um processo relativamente paulatino, na sucessão das coortes. Pode-se ver no gráfico que a linha da educação média, de cor mais escura, exceto em P25*, vai de forma encadeada se aproximando do nível zero, que equivale à educação fundamental.

Os retornos de renda da educação superior, para a mulher com origem no agrupamento destituído, 
evoluíram de forma diferenciada a depender do nível da distribuição (Gráfico 6). Os retornos da educação subiram bastante em P25 (+0,513) e um pouco em P50*. Por outro lado, tiveram um decréscimo de -0,361 em P75, e de -0,630 em P90* (IC de $-1,552$ a +0,292). As mudanças em P50* e P90* não foram estatisticamente significativas, mas $\mathrm{O}$ intervalo de confiança em $\mathrm{P} 90^{*}$ tende muito para o valor negativo. Nos níveis superiores, os decréscimos foram progressivos entre as coortes. Ao olhar para o desempenho dentro de cada universo de gênero, na última coorte o retorno da mulher se mostra superior ao do homem em P25 (+0,511), menor em P75 (-0,223), e equivalente em P50* e P90*. Este quadro geral mais favorável à mulher, na comparação com o homem, representa uma reversão do que predominava na primeira coorte.

Os retornos da educação média aumentaram em P25 (0,391), porém caíram em P75 (-0,558) e em P90 (-0,813), entre a primeira e última coorte. Em P50 continuou em patamar tão baixo quanto o registrado na primeira coorte, em P25. No nível de renda mais alto (P90), a vantagem caiu de 1,115 para 0,302 . O quadro delineado representa um grande complicador, tendo em vista que a aquisição deste nível de escolaridade, em vez do superior completo, representa um passo mais factível quando se parte da origem destituída.

A comparação de gênero mostra que a origem destituída gerou perdas convergentes na educação superior e na educação média, imponto a ambos os grupos um ônus comum. Tais perdas, porém, foram mais amplas ou fortes para os homens. As alteraçóes na educação superior fizeram com que, na última coorte, entre pares de gênero, as desvantagens de retornos da mulher se revertessem (P25), se reduzissem (P75) ou se tornassem incertas ( $\mathrm{P} 50^{*}$ e P90*). As perdas masculinas mais acentuadas aproximaram os retornos aos níveis mais baixos da mulher, ou mais rebaixados do homem. Na medida em que estas perdas dizem respeito à origem destituída, cuja trajetória depende fortemente da mediação educacional, cria-se para ela certa convergência relativa perversa no solapamento das oportunidades de filhos e filhas obterem melhor renda.
Feito este percurso de descrição e análise, podese concluir que a evoluçáo dos retornos da educação para a origem no topo foi mais favorável, ou menos desfavorável, do que para o agrupamento destituído. Entre a primeira e a última coorte, ocorreram reduções até P75. Esta queda se concentrou na última coorte. Nas coortes intermediárias, no entanto, ocorrem elevaçôes dos retornos. Trata-se, assim, de uma tendência mais recente, e não de longo prazo. Além disso, no tocante aos retornos da educação superior completa, esta tendência não afetou a renda no topo da distribuiçáo (P90). Isto significa que o processo não comprometeu o componente central de reprodução social da origem no topo social. A manutenção dos retornos da educação superior neste nível da distribuição favorece em muito a disputa desta origem pelas rendas mais elevadas, na fronteira dos $10 \%$ mais ricos.

A evolução dos retornos da educação para a origem no agrupamento destituído mostra um quadro bem mais desfavorável. Os retornos da educação superior caíram em todos os níveis, no universo masculino, e nos níveis superiores, no universo feminino (P75 e P90). Além disso, fazem parte de uma dinâmica de longo prazo, constante e progressiva. A tendência mais crítica diz respeito aos retornos da educação média. O declínio foi extremamente forte para o homem, e bem expressivo para a mulher. Para elas, além disso, a queda no nível mais alto (P90) foi dramática. Os retornos da educação caíram de modo mais acerbo justamente no âmbito da transição educacional mais factível, e com potencial de envolver uma parcela maior do grupo. O quadro configurado sinaliza aumentos apreciáveis dos constrangimentos às oportunidades de ganhos de renda via educação média a partir desta origem.

Estimativas do resultado predominante no universo de casos, realizadas à parte com o mesmo modelo interativo, mas sem separação por gênero, confirmam as tendências menos desfavoráveis para a origem no topo social e as consequências mais adversas para a origem no agrupamento destituído. $\mathrm{O}$ processo de queda dos retornos para a origem privilegiada não prosperou no topo da distribuição de renda (P90), o que é bastante significativo, pois tem implicaçóes apreciáveis na transmissão das desigualdades no que 
mais importa para esta origem (os 10\% mais ricos) e a reprodução da desigualdade nela ancorada. Além disso, as retraçóes que ocorreram abaixo de P90 náo representam tendências que vieram de longe, pois a evolução foi positiva nas coortes intermediárias.

\section{Discussão e conclusão}

As quatro questóes investigadas representam diferentes dimensões do processo de transmissão das desigualdades socioeconômicas na sociedade. A configuração geral da associação entre origem e destino envolve as tendências dominantes em cada dimensão. Na estratégia analítica, a visão sintética de conjunto deve emergir das determinaçôes parciais e de suas interconexōes. Este é o percurso para se chegar à generalizaçáo empírica do fenômeno complexo formado por nexos diretos e indiretos, que podem divergir em força e sentido, entre origem, educação e destino.

A primeira questáo de pesquisa é respondida de forma afirmativa para a origem no topo e em empregado qualificado. Ao considerar o conjunto dos casos destas origens, em cada universo de gênero, vê-se uma forte associação direta entre origem $\mathrm{e}$ destino, não mediada pela educação. A associaçẫo é mais forte entre os homens. É bem forte, embora algo menos, nos níveis superiores da distribuição. Em geral, nas demais origens, a associação direta não somente persiste, como o efeito direto supera o efeito total, o que representa uma forma especial de manifestaçáo da força da origem. Nestes casos, a educação representa um domínio de "mediação negativa". Existe uma desvantagem educacional de origem que, se fosse removida, projetaria uma renda melhor para os filhos. A educação não é uma força autônoma, nesta situação, pois está muito condicionada, no sentido negativo, pela origem de classe.

Embora a análise empreendida esteja voltada para o estabelecimento de associaçóes empíricas, com o uso de controles não decorrentes da origem social e antecedentes à inserção econômica, as dimensôes causais de fundo das questóes investigadas devem ser ponderadas. $\mathrm{O}$ efeito direto da origem social pode estar superestimado, na medida em que não são controlados todos os aspectos observáveis e relevantes associados às dimensóes verticais e horizontais da educação, de modo a captar mais amplamente a heterogeneidade educacional (Hällsten, 2013; Bernardi e Gil-Hernández, 2020, p. 5-6). Por outro lado, a abordagem consagrada do papel mediador da educação, ao deixar de controlar pela seleçấo endógena ou não aleatória na aquisição educacional, superestima os retornos da educaçáo (Karlson, 2019, p. 226). Além disso, a ausência de controle da formação inicial de qualificações cognitivas e não cognitivas, que precedem e independem da escolaridade formal, acaba por superestimar o papel da mediaçáo educacional (Karlson e Birkelund, 2019). Por fim, como o estudo náo agrega à classe social outros indicadores de origem, como a educação dos pais, o efeito de origem está possivelmente subestimado (Gugushvili, Budoki e Goldthorpe, 2017). Os efeitos diretos constatados são muito marcantes. Como vimos, as questóes de mensuração da educação, ao atuar em direções opostas, podem eventualmente se anular. No caso do Brasil, porém, os fatores nâo considerados parecem mais subestimar o efeito da origem social.

A resposta à segunda questáo da pesquisa é negativa para a origem no topo social. $O$ efeito direto da origem no topo, em relação à origem destituída, náo declinou no tempo entre as coortes. Entre as mulheres, o efeito direto era nulo na primeira coorte e ficou expressivo a partir da segunda. Não é certo, por outro lado, que o efeito total tenha diminuído para as mulheres. Entre os homens, não é certo que o efeito direto, não mediado pela educação, tenha declinado na origem privilegiada. $\mathrm{O}$ resultado agregado que emerge da combinação entre as tendências de gênero é de um inequívoco aumento do efeito direto da origem privilegiada. Não é certo que tenha aumentado o papel mediador da educaçáo, já que a associação intergeracional líquida não caiu. Além disso, o controle da educação atua em direçóes contrárias no topo e na base social; em um caso, reduz o efeito, pois remove uma vantagem educacional; no outro, $\mathrm{o}$ amplifica, pois suprime uma desvantagem educacional de origem. Esta inversão acarreta certa subestimação do efeito direto da origem no topo social, quando contrastado com o agrupamento destituído.

Os problemas já discutidos na primeira questáo de pesquisa poderiam afetar a trajetória temporal na 
medida em que tivessem implicaçóes diferenciadas entre as coortes. $\mathrm{O}$ estudo usou efeitos interativos entre educação e coorte, visando captar diferenças na distribuição e nos retornos da educação entre as coortes que pudessem afetar o resultado final. A diferenciação horizontal da educação, cujo controle não foi factível, seria mais importante para a última coorte e, neste sentido, afetaria a comparação com a primeira. Entretanto, embora exista um cenário não observável de décadas, no elo entre origem e destino, o que é comum neste tipo de estudo, os fatores ausentes no desenho da investigação parecem, no agregado, representar tendências mais seletivas do que propriamente equalizadoras.

O quadro de aumento do efeito direto associou-se, no entanto, a uma diminuição (de montante incerto) do efeito total em níveis superiores da distribuição. Demanda esclarecimento tal diminuição, observada no patamar geral da vantagem de origem. Esta evolução do efeito total é diferente do que foi constatado em estudo anterior ao nível da média de renda dos filhos (Figueiredo Santos, 2020). Estimativa à parte feita pelo autor, usando modelo com controles e interaçóes similares, revela que a renda média predita está em geral próxima de P70 (de cada grupo) nas diferentes origens de classe. No topo, está mais perto de P66. Este fenômeno reflete o fato de a distribuição da renda no Brasil ser extremamente assimétrica, ou desequilibrada na direção dos valores mais altos. Não quer dizer que este percentil seja equivalente à média; ele representa um nível limiar em um ordenamento da distribuição. A média é uma medida que recebe a influência de todos os valores da distribuição. A renda média é influenciada pelas rendas extremamente altas que existem entre aqueles que auferem rendas mais altas. É provável que esta propriedade da média, como medida central sumária, retrate de um modo especial a influência de um excesso muito elevado de renda em uma parcela dos que, vindos da origem no topo social, se tornaram ricos.

Essas ponderaçôes relativizam o sentido ou a implicação do que foi mensurado como queda do efeito total em percentis mais altos. Nas últimas décadas, a origem de classe privilegiada tem mantido, no destino, vantagens bastante expressivas em oportunidades de vida no Brasil. Além disso, não é certo que esta vantagem de origem, na comparação com o polo destituído, tenha tido uma redução ponderável no curso de tempo observado.

A resposta à terceira questão de pesquisa também é negativa para a hipótese equalizadora. $\mathrm{O}$ efeito da origem de classe privilegiada, em geral, não é menor no grupo com curso superior completo. Nos níveis superiores da distribuição (P75 e P90), não é certo que exista uma diferença entre a educação média (combinada à superior incompleta) e a educação superior completa. As vantagens de classe em ambos os níveis educacionais são apreciáveis. Este resultado, com variaçóes, se confirma nos universos feminino e masculino. Existe uma diferença entre associação empírica e efeito causal de se ter educação superior. Estudos recentes demonstram que a associação entre educação superior e menor efeito direto da origem, quando existe, é devida aos processos de "seleção" endógena de pessoas predispostas à mobilidade, e não ao papel equalizador da educação superior (Zhou, 2019; Oh e Kim, 2020). A mobilidade entre geraçóes entre quem possui educação superior está estreitamente ligada à estratificação dentro deste segmento. A noção de que a educação superior seria o grande equalizador social, sugerida em estudos anteriores, alimenta-se da desconsideração de "informações detalhadas sobre a estratificação vertical e horizontal no ensino superior" (Oh e Kim, 2020, p. 14).

Quaisquer fatores não controlados que influenciem a educação e estejam associados à origem socioeconômica podem ser uma fonte real de interaçôes entre origem e educação. É difícil prever quais padrōes de seleção diferenciada entre níveis educacionais - e suas consequências empíricas poderiam gerar fontes espúrias de interação entre origem e educaçáo, em particular quando se avalia o viés de seleção somente com variáveis observáveis (Fiel, 2020, p. 356-7). A presente investigação, embora não tenha um desenho causal, mostra uma evidência contrária à tese equalizadora, já que não observa associação empírica entre educação superior e menor efeito direto da origem social. A educação superior não representa um domínio capaz de nivelar as discrepâncias de origem, no curso da trajetória em direção ao destino. Esta constatação é bastante marcante no aspecto demográfico, já que resulta de 
contraste com vasto conjunto de agrupamentos de origem de classe com renda inferior.

O efeito direto da origem privilegiada, por outro lado, provê uma apreciável vantagem compensatória, que reforça a renda de quem fracassa na trajetória educacional. Análise empírica recente do sociólogo que elaborou o conceito, usando uma estratégia de desagregaçāo dos grupos ocupacionais, demonstrou que tal vantagem compensatória tende a estar associada a posiçóes de comando de nível médio-baixo no setor de serviços, que não requerem credenciais mais elevadas, mas demandam recursos econômicos e qualificaçôes não cognitivas transmitidas pela origem privilegiada. Representaria um componente inerente à lógica de reprodução de classe e, neste sentido, relativamente não afetada por fatores institucionais (Bernardi e Gil-Hernández, 2020, p. 13-4).

$\mathrm{Na}$ resposta à quarta questão de pesquisa, pode-se concluir que os retornos da educação superior completa estáo caindo para homens e mulheres. Esta queda é mais forte nos níveis superiores da distribuição. Em ambos os grupos, os retornos da educação média tiveram igualmente retraçóes expressivas nos níveis superiores da distribuição. A queda dos retornos da educação superior completa entre os homens foi generalizada, mais forte e contínua no transcurso das coortes.

$\mathrm{Na}$ estimativa diferenciada por origem de classe, a quarta questão recebeu um tratamento mais longo, por envolver estimativas de efeitos nas combinaçôes de origem de classe, gênero e coorte. Por outro lado, em função da multiplicidade de situações, a análise se concentrou nos agrupamentos polares. Os retornos da educação para a origem no topo social evoluíram claramente de forma mais favorável, ou menos desfavorável, que na origem destituída. Mesmo o quadro "menos desfavorável" favorece bastante, no sentido comparativo, quem já tinha grandes vantagens. Homens e mulheres vindos do topo social, com educação superior completa, conseguiram reproduzir as vantagens de origem na disputa por rendas mais elevadas ao nível dos 10\% mais ricos. Por outro lado, na origem destituída, com variaçôes de gênero, predominou o declínio dos retornos da educação superior e média.
Para a mulher, não houve queda na educação média ao nível da mediana; ela manteve a grande desvantagem da primeira coorte. As quedas de retorno da educação média e superior incompleta têm consequências negativas especialmente problemáticas. No grupo destituído, os decréscimos foram expressivos ou muito fortes neste recurso mais acessível. Isto significa que o acesso à educação média não está realizando, em termos de oportunidades de vida, o potencial de beneficiar um maior número de oriundos deste grupo que se empenham em progredir na educação. Estudo longitudinal recente com metodologia diferenciada, que ajusta por seletividade e erros de mensuração, produziu resultados que contestam o papel equalizador da educaçáo superior; ele registra, nos Estados Unidos, um efeito equalizador associado ao limiar de conclusão do ensino médio entre os que vêm de origem desvantajosa (Fiel, 2020, p. 367-8). Embora no Brasil este nível tenha tido o maior crescimento (Tabela 1), o contraste parece paradoxal, já que o país experimentou uma expansão educacional relativamente mais recente e bem menor. $\mathrm{O}$ resultado parece sinalizar um rebaixamento bem prematuro do potencial de mobilidade social da educação média, talvez menos considerada, mas de maior implicação populacional.

Importantes variaçōes nos efeitos proporcionais de renda estão associadas às divisōes de gênero. A análise de mobilidade social delineada nos gráficos não focaliza as diferenças absolutas de renda no confronto direto entre homens e mulheres. Estáo em questão as trajetórias em cada universo de gênero, os possíveis contrastes e as implicaçōes das tendências. As interações revelam que fatores associados ao gênero afetariam a conversão do efeito de origem em resultados no destino. O grau de desigualdade baseada em origem entre as mulheres ficou mais próximo daquele existente entre os homens. Os processos que afetam o valor da educação tendem potencialmente a influenciar mais na mobilidade social da mulher. O homem de baixa educaçáo se beneficia mais da vantagem compensatória da origem privilegiada. A distância de renda entre origens de classe ficou maior para as mulheres que adquirem educação superior. Ocorreram retraçóes nas discrepâncias de gênero nos retornos da educação superior, em termos proporcionais, com perdas maiores no universo masculino. Quando se tem origem no topo social, a educaçấo superior preserva 
os retornos proporcionais entre homens e mulheres ao nível superior da distribuição da renda. A mulher de origem privilegiada tem mais a perder, ou menos a obter, quando não adquire educação superior. Na origem destituída, os retornos da educação superior e média mostram grandes perdas para ambos os grupos, porém mais intensas para os homens. Na origem destituída, ocorre uma perversa convergência proporcional no rebaixamento de oportunidades de filhos e filhas obterem renda melhor.

Os estudos realizados investigaram os processos de mobilidade social no Brasil focalizando classe social na origem e diferentes resultados no destino. Foram estudados os efeitos de origem no acesso ao topo social, na renda média e em diferentes níveis de renda dos filhos. Neste artigo, foram contempladas também as interaçóes da origem com gênero. Aspectos centrais dos resultados se revelaram convergentes nas quatro questóes comuns investigadas. Os resultados observados realçam, para o campo de estudos, a importância de investigar a relação entre origem e destino, sem desconsiderar o impacto de mudanças estruturais. Estimativas qualificadas sobre os nexos entre origem, educação e destino, que incorporam a operação subjacente de forças estruturais, podem lançar luz diferenciada, complementar e enriquecedora às tendências gerais da mobilidade social.

Os resultados deste artigo vêm se somar às realizações de estudos recentes que usam modelos de regressão para investigar o papel da educação na mobilidade social contemporânea. $\mathrm{O}$ trabalho demonstra a força persistente do efeito direto da origem social privilegiada. Confirma a queda dos retornos da educação, um elo crítico no triangulo analítico da mobilidade social, mas mostra que esta tendência foi mais favorável na origem privilegiada. Coloca em questáo, no contexto da sociedade brasileira, a hipótese do papel da educação superior como equalizador das desigualdades de origem. Apresenta uma generalização empírica diferenciada, já que os estudos recentes que contestam a tese equalizadora estáo baseados na realidade dos países mais desenvolvidos.

\section{Notas}

1 As estimativas potencialmente mais problemáticas, com quatro interaçóes, diriam respeito aos níveis mais elevados de renda para a mulher de origem destituída. Entretanto, nesta situaçáo, muitos casos vieram desta origem, mesmo que a proporçáo seja pequena, e a amostra tem um equilíbrio de gênero, pois o entrevistado foi selecionado aleatoriamente no domicílio. O problema não seria impeditivo para a análise, como mostra o comentário relativo à mulher no Gráfico 6 .

2 Uma interpretaçáo alternativa proposta por Goldthorpe considera que a associação entre educação e destino varia a depender dos diferentes tipos ou níveis de origem. Neste sentido, em função do grau de não dependência do recurso educacional e da disponibilidade de recursos alternativos, quanto maior a vantagem de origem, menor seria a associação, e vice-versa (Goldthorpe, 2013).

\section{BIBLIOGRAFIA}

ANGRIST, Joshua David \& PISCHKE, Jörn-Steffen. (2009), Mostly harmless econometrics: an empiricist's companion. Princeton, Princeton University Press.

BERNARDI, Fabrizio. (2014), "Compensatory advantage as a mechanism of educational inequality: a regression discontinuity based on month of birth". Sociology of Education, 87, 2:74-88. Disponível em https://doi.org/10.1177/0038040714524258, consultado em 22/04/2021.

BERNARDI, Fabrizio \& BALLARINO, Gabriele. (2014), "Participation, equality of opportunity and returns to tertiary education in contemporary Europe". European Societies, 16, 3:422-42. Disponível em https://doi.org/10.1080/14616 696.2012.750729, consultado em 22/04/2021.

BERNARDI, Fabrizio \& BALLARINO, Gabriele. (2016a), Education, occupation and social origin: a comparative analysis of the transmission of socioeconomic inequalities. Cheltenham, Edward Elgar Publishing.

BERNARDI, Fabrizio \& BALLARINO, Gabriele. (2016b), "Introduction: education as the great equalizer: a theoretical framework", in F. Bernardi \& G. Ballarino (orgs.), Education, occupation and social origin. Cheltenham, Edward Elgar Publishing.

BERNARDI, Fabrizio \& GIL-HERNÁNDEZ, Carlos J. (2020), "The social-origins gap in labour market outcomes: compensatory and boosting 
advantages". European Sociological Review, 37, 1:32-48. Disponível em https://doi.org/10.1093/ esr/jcaa034, consultado em 22/04/2021.

BREEN, Richard \& JONSSON, Jan O. (2007), "Explaining change in social fluidity: educational equalization and educational expansion in twentieth-century Sweden". American Journal of Sociology, 112, 6:1775-1810. Disponível em https://doi.org/10.1086/508790, consultado em 22/04/2021.

BREEN, Richard; MOOD, Carina; JONSSON, Jan O. (2016), "How much scope for a mobility paradox? the relationship between social and income mobility in Sweden”. Sociological Science, 3: 39-61. Disponível em https://doi.org/10.15195/ v3.a3, consultado em 22/04/2021.

BUKODI, Erzsébet \& GOLDTHORPE, John. (2020), "Primary factors in intergenerational class mobility in Europe: results from the application of a topological model". European Sociological Review, 37, 1”1-17. Disponível em https://doi.org/10.1093/esr/jcaa028, consultado em 22/04/2021.

CAMERON, A. Colin \& TRIVEDI, Pravin K. (2009), Microeconometrics using Stata. College Station, Stata Press.

CRUZ, Gabriela Freitas da. (2019) Mobilidade intergeracional de renda no Brasil: tendências temporais e diferenciais de gênero. Tese de Doutorado. Instituto de Economia, Universidade Federal do Rio de Janeiro, Rio de Janeiro.

FIEL, Jeremy E. (2020), “Great Equalizer or Great Selector? Reconsidering Education as a Moderator of Intergenerational Transmissions". Sociology of Education, 93, 4:353-71. Disponível em https://doi.org/10.1177/0038040720927886, consultado em 22/04/2021.

FIGUEIREDO SANTOS, José Alcides. (2005), "Uma classificação socioeconômica para o Brasil". Revista Brasileira de Ciências Sociais, 20, 58:2745. Disponível em http://dx.doi.org/10.1590/ S0102-69092005000200002, consultado em 22/04/2021.

FIGUEIREDO SANTOS, José Alcides. (2010), "Comprehending the class structure specificity in Brazil”. South African Review of Sociology, 41,
3:24-44. Disponível em http://dx.doi.org/10.1 080/21528586.2010.516119, consultado em 22/04/2021.

FIGUEIREDO SANTOS, José Alcides. (2014), "Esquema de classe para abordar a desigualdade de saúde no Brasil", in F. Rosenberg (org.), Classes sociais, território e saúde: questóes metodológicas e politicas. Rio de Janeiro, Editora Fiocruz. Disponível em https://forumitaborai.fiocruz.br/ node/896, consultado em 22/04/2021

FIGUEIREDO SANTOS, José Alcides. (2019), "Origem de classe e destino ao topo social no Brasil”. Revista Brasileira de Sociologia, 7, 16:82104. Disponível em http://www.sbsociologia.com. br/rbsociologia/index.php/rbs/article/view/492, consultado em 22/04/2021.

FIGUEIREDO SANTOS, José Alcides. (2020), "Origem de classe e chances de vida no Brasil". Revista de Ciências Sociais, 51, 1:249-90. Disponível em http://dx.doi.org/10.36517/rcs.51.1.a02, consultado em 22/04/2021.

FIGUEIREDO SANTOS, José Alcides; SCALON, Celi (2018), "Desigualdade e estratificação social no Brasil”, in S. Miceli e C.B. Martins, Sociologia Brasileira hoje II. São Paulo, Ateliê Editorial.

FOX, Liana; TORCHE, Florencia; WALDFOGEL, Jane. (2016), "Intergenerational inequality", in D. Brady e L. M. Burton, The Oxford handbook of the social science of poverty. Oxford, Oxford University Press.

GERRING, John. (2012), Social science methodology: a criterial framework. 2a edição. Cambridge, Cambridge University Press.

GOLDTHORPE, John. (2013), "The myth of education-based meritocracy”. Progressive Review, 10, 4:234-9. Disponível em https:// doi.org/10.1046/j.1468-0041.2003.00324.x, consultado em 22/04/2021.

GOLDTHORPE, John. (2016), "Social class mobility in modern Britain: changing structure, constant process". Journal of the British Academy, 4: 89111. Disponível em https://doi.org/10.5871/ jba/004.089, consultado em 22/04/2021.

GUGUSHVILI, Alexi; BUDOKI, Erzsébet; GOLDTHORPE, John. (2017), "The direct effect of social origins on social mobility chances: 'glass 
floors' and 'glass ceilings' in Britain". European Sociological Review, 33, 2:305-316. Disponível em https://doi.org/10.1093/esr/jcx043, consultado em 22/04/2021.

HÄLLSTEN, Martin. (2013), “The class-origin wage gap: heterogeneity in education and variations across market segments". The British Journal of Sociology, 64, 4: 662-90. Disponível em https:// doi.org/10.1111/1468-4446.12040, consultado em 22/04/2021.

HANSEN, Marianne. (2001), "Education and economic rewards: variations by social class origin and income measures". European Sociological Review, 17, 3:209-31. Disponível em https:// doi.org/10.1093/esr/17.3.209, consultado em 22/04/2021.

HOUT, Michael (1988), "More universalism, less structural mobility: the American occupational structure in the 1980s". American Journal of Sociology, 93, 6:1358-1400. Disponível em https://doi.org/10.1086/228904, consultado em 22/04/2021.

HOUT, Michael (2012), "Social and economic returns to college education in the United States". Annual Review of Sociology, 38: 379-400. Disponível em https://doi.org/10.1146/annurev. soc.012809.102503, consultado em 22/04/2021.

KAM, Cindy; FRANZESE JR., Robert J. (2007), Modeling and interpreting interactive hypotheses in regression analysis: a refresher and some practical advice. Ann Arbor, University of Michigan Press.

KARLSON, Kristian Bernt. (2019), "College as equalizer? Testing the selectivity hypothesis". Social Science Research, 80:216-229. Disponível em https://doi.org/10.1016/j.ssresearch.2018.12.001, consultado em 22/04/2021.

KARLSON, Kristian Bernt \& BIRKELUND, Jesper Fels. (2019), "Education as a mediator of the association between origins and destinations: the role of early skills". Research in Social Stratification and Mobility, 64, 100436:1-9. Disponível em https://doi.org/10.1016/j.rssm.2019.100436, consultado em 22/04/2021.

LONG, J. Scott \& FREESE, Jeremy Jay. (2014), Regression models for categorical dependent variables using Stata. 3a edição, College Station, Stata Press.
OH, Byeongdon \& KIM, ChangHwan. (2020), "Broken promise of college? New educational sorting mechanisms for intergenerational association in the 21 st century". Social Science Research, 86, 102375:1-15. Disponível em https:// doi.org/10.1016/j.ssresearch.2019.102375, consultado em 22/04/2021.

PERO, Valéria Lúcia \& SZERMAN, Dimitri Joe de Alencar. (2008), "Mobilidade intergeracional de renda no Brasil". Pesquisa e Planejamento Econômico, 38, 1:1-35.

PICANÇO, Felícia Silvia. (2006), "Os estudos de mobilidade social e ocupacional: passado, presente e desafios para o futuro". BIB, 62, 2:87-102. Disponível em http://www.anpocs.com/index. php/edicoes-anteriores/bib-62, consultado em 22/04/2021.

RIBEIRO, Carlos Antônio Costa. (2007), Estrutura de classe e mobilidade social no Brasil. Bauru, Edusc.

RIBEIRO, Carlos Antônio Costa. (2012), "Quatro décadas de mobilidade social no Brasil". Dados - Revista de Ciências Sociais, 55, 3:641-79. Disponível em http://dx.doi.org/10.1590/ S0011-52582012000300003, consultado em 22/04/2021.

RIBEIRO, Carlos Antônio Costa. (2014), "Mobilidade e estrutura de classes no Brasil contemporâneo". Sociologias, 16, 37:178-217. Disponível em http:// dx.doi.org/10.1590/15174522-016003711, consultado em 22/04/2021.

RIBEIRO, Carlos Antônio Costa. (2017a), "Occupational and Income Intergenerational mobility in Brazil Between the 1990's and 2000's'. Sociologia \& Antropologia, 7, 1:157-185. Disponível em https://doi.org/10.1590/2238-38752017v717, consultado em 22/04/2021.

RIBEIRO, Carlos Antônio Costa. (2017b), "Tendências da desigualdade de oportunidades no Brasil: mobilidade e estratificação educacional". Mercado de Trabalho: conjuntura e análise, 62:49-65.

RIBEIRO, Carlos Antônio Costa \& CARVALHAES, Flávio. (2020), "Estratificação e mobilidade social no Brasil: uma revisão da literatura na sociologia de 2000 a 2018”. BIB, 92:1-46.

RIDGEWAY, Cecília L. (2012), Framed by gender. Oxford, Oxford University Press. 
SCALON, Maria Celi Ramos da Cruz. (1999), Mobilidade social no Brasil. Rio de Janeiro, Renavan.

SCALON, Maria Celi Ramos da Cruz. (2009), Ensaios de estratificação. Belo Horizonte, Argumentum.

SCALON, Maria Celi Ramos da Cruz \& FIGUEIREDO SANTOS, José Alcides. (2010), "Desigualdades, classes e estratificação", in H. T. S. Martins (org.), Horizontes das ciências sociais no Brasil (sociologia). São Paulo, Anpocs/ Barcarolla/ Discurso Editorial.

SCHENKER, Nathaniel \& GENTLEMAN, Jane F. (2001), "On judging the significance of differences by examining the overlap between confidence intervals". American Statistician, 55, 3:182-186.

TORCHE, Florencia. (2015a), "Analyses of intergenerational mobility: an interdisciplinary review". The ANNALS of the American Academy of Political and Social Science, 657:37-62. Disponível em https://doi.org/10.1177/0002716214547476, consultado em 22/04/2021.

TORCHE, Florencia. (2015b), "Intergenerational mobility and equality of opportunity". European Journal of Sociology, 53, 6: 343-371. Disponível em https://doi.org/10.1017/S0003975615000181, consultado em 22/04/2021.
TORCHE, Florencia. (2016), "Education and the intergenerational transmission of advantage in the US", in F. Bernardi \& G. Ballarino (orgs), Education, occupation and social origin. Cheltenham, Edward Elgar Publishing.

TORCHE, Florencia \& RIBEIRO, Carlos Antônio Costa. (2010), "Pathways of change in social mobility: industrialization, education and growing fluidity in Brazil". Research in Social Stratification and Mobility, 28, 3:291-307. Disponível em https://doi.org/10.1016/j.rssm.2010.03.005, consultado em 22/04/2021.

WITTEVEEN, Dirk \& ATTEWELL, Paul. (2020), "Reconsidering the meritocratic power of a college degree". Research in Social Stratification and Mobility, 66, 100479:1-14. Disponível em https://doi.org/10.1016/j.rssm.2020.100479, consultado em 22/04/2021.

WRIGHT, Erik Olin. (1997), Class counts: comparative studies in class analysis. Cambridge, Cambridge University Press.

ZHOU, Xiang. (2019), "Equalization or selection: reassessing the 'meritocratic power' of a college degree in intergenerational income mobility". American Sociological Review, 84, 3:459-85. Disponível em https://doi.org/10.1177/00031224198449925, consultado em 22/04/2021. 


\section{ORIGEM DE CLASSE, GÊNERO E TRANSMISSÁO DAS DESIGUALDADES NO BRASIL}

\section{José Alcides Figueiredo Santos}

Palavras-chave: Classe Social, Mobilidade Social, Desigualdade de Oportunidades, Renda, Gênero.

O trabalho trata da transmissão intergeracional das desigualdades socioeconômicas usando dados recentes para o Brasil (PNAD 2014). Neste sentido, investiga a associação total e direta entre origem de classe e renda dos filhos, a evoluçáo temporal desta associação, a associação direta em diferentes níveis de educação e a evolução dos retornos da educação, em geral e por origem de classe. Os padrôes de associação são analisados considerando suas variaçóes por gênero e níveis da distribuição da renda. O estudo utiliza regressão quantílica e estima diferenças proporcionais na renda dos filhos para demonstrar a força persistente do efeito direto da origem social privilegiada. Revela que a queda dos retornos da educaçáo teve uma evolução mais favorável para a origem no topo social. Coloca em questão, para a sociedade brasileira, a hipótese do papel equalizador da educação superior nas desigualdades de origem, e mostra o papel de gênero na conversáo do efeito de origem em resultados no destino. Assim, lança uma luz diferenciada sobre tendências da mobilidade social no Brasil.

\section{ORIGIN OF CLASS, GENDER AND TRANSMISSION OF INEQUALITIES IN BRAZIL}

\section{José Alcides Figueiredo Santos}

Keywords: Social class, social mobility, inequality of opportunities, income, gender.

The article deals with the intergenerational transmission of socioeconomic inequalities using recent data for Brazil (PNAD 2014). In this sense, it investigates the total and direct association between class origin and children's income, the temporal evolution of this association, the direct association at different levels of education and the evolution of education returns, in general and by class origin. The patterns of association are analyzed considering their variations by gender and levels of income distribution. The study uses quantile regression and estimates proportional differences in children's income to demonstrate the persistent strength of the direct effect of the privileged social origin. It reveals that the fall in the returns to education had a more favorable evolution from the origin at the social top. It calls into question, for Brazilian society, the hypothesis of the equalizing role of higher education in inequalities of origin, and shows the role of gender in converting the effect of origin into results in the destination. Thus, it sheds a different light on trends in social mobility in Brazil.

\section{ORIGINE DE LA CLASSE, GENRE ET TRANSMISSION DES INÉGALITÉS AU BRÉSIL}

\section{José Alcides Figueiredo Santos}

Mots clés: classe sociale, mobilité sociale, inégalité des chances, revenu, sexe.

L'article traite de la transmission intergénérationnelle des inégalités socioéconomiques à partir de données récentes pour le Brésil (PNAD 2014). En ce sens, il étudie l'association totale et directe entre l'origine de classe et le revenu des enfants, l'évolution temporelle de cette association, l'association directe à différents niveaux d'éducation et l'évolution des rendements de l'éducation, en général et par origine de classe. Les modèles d'association sont analysés en tenant compte de leurs variations selon le sexe et les niveaux de répartition des revenus. L'étude utilise une régression quantile et estime les différences proportionnelles dans le revenu des enfants pour démontrer la force persistante de l'effet direct de l'origine sociale privilégiée. Il révèle que la baisse des rendements de l'éducation a eu une évolution plus favorable vers l'origine au sommet social. Elle remet en cause, pour la société brésilienne, l'hypothèse du rôle égalisateur de l'éducation supérieur dans les inégalités d'origine, et montre le rôle du genre dans la conversion de l'effet d'origine en résultats dans la destination. Ainsi, il jette un éclairage différent sur les tendances de la mobilité sociale au Brésil. 